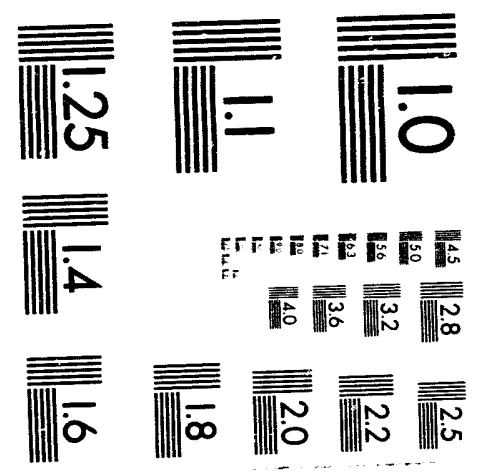



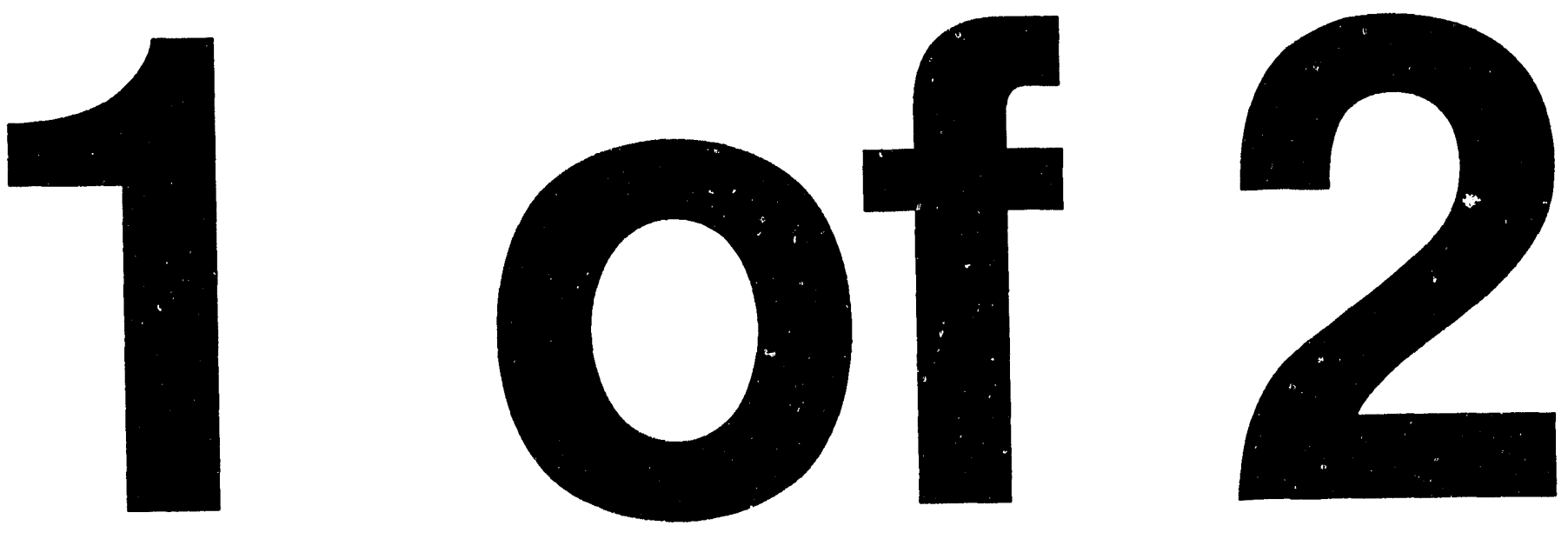


\section{RECOMMENDATIONS FOR \\ IMPROVEMENTS TO \\ PROGRAM AND PROJECT MANAGEMENT}

Matrix Management Upgrade Solutions Team

(MMUST)

H. R. Yook

N. H. Cutshall

F. J. Homan

A. P. Malinauskas

R. C. Mason

J. Sheffield

D. N. Smith

S. H. Stow

R. C. Ward

J. R. Weir, Jr.

January 1994

Prepared for the

Oak Ridge National Laboratory Division/Program/

Office Directors Caucus

Prepared by

OAK RIDGE NATIONAL LABORATORY

P. O. Box 2008

Oak Ridge, Tennessee 37831-6040

managed by

MARTIN MARIETTA ENERGY SYSTEMS, INC.

for the

U.S. DEPARTMENT OF ENERGY

under contract DE-AC05-84OR21400 


\section{CONTENTS}

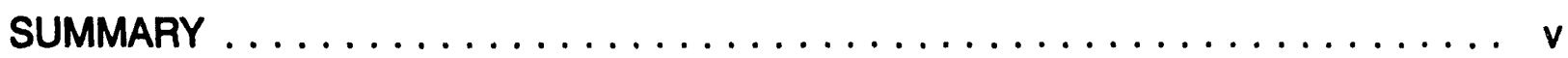

1. INTRODUCTION $\ldots \ldots \ldots \ldots \ldots \ldots \ldots \ldots \ldots \ldots \ldots \ldots \ldots \ldots \ldots \ldots$

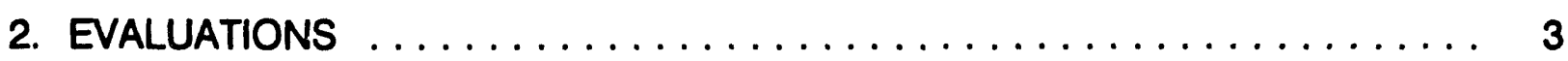

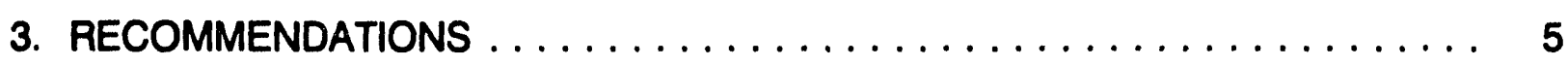

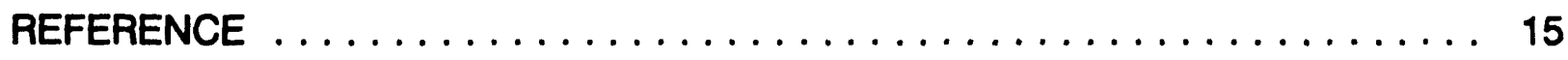

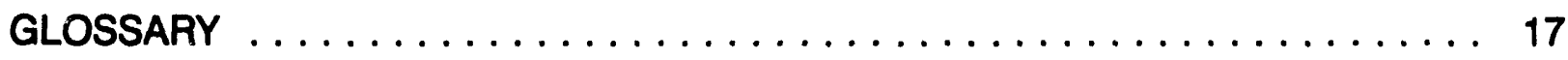

Appendix A. STATEMENTS OF CONCERN $\ldots \ldots \ldots \ldots \ldots \ldots \ldots \ldots \ldots$ A-1

Appendix B. MATRIX MANAGEMENT UPGRADE SOLUTIONS TEAM CHARTER . B-1

Appendix C. SUCCESSFUL PROGRAM/PROJECT SUMMARY DESCRIPTIONS . C-1

Appendix D. PERFORMANCE OF THE ORNL MATRIX MANAGEMENT SYSTEM:

SUMMARY OF RESPONSES FROM DOE HEADQUARTERS

PROGRAM MANAGERS $\ldots \ldots \ldots \ldots \ldots \ldots \ldots \ldots \ldots \ldots \ldots \ldots \ldots \ldots \ldots$

Appendix E. SUMMARY OF INFORMATION GATHERED $\ldots \ldots \ldots \ldots \ldots$ E-1 


\section{SUMMARY}

Oak Ridge National Laboratory (ORNL) has operated with a balanced matrix organization for over sixteen years. Much of the work at the Laboratory is accomplished with good customer satisfaction through programs, projects, and matrix management. During the past several years concerns about program and project management at ORNL have been expressed by both the Department of Energy and ORNL staff.

In May 1993 the ORNL Division/Program/Office Directors Caucus chartered a "fox team" to identify and to recommend improvements to matrix management that would lead to resolution of these concerns. Nine experienced ORNL staff members served on this Matrix Management Upgrade Solutions Team (MMUST).

The MMUST adopted a four-phase approach in which they first gathered information and then developed and proposed recommended actions. In the fourth phase the team was available to support implementation of the recommendations. They began work in June 1993, gathering and evaluating information in biweekly meetings for six months. Recommendations developed in October and November 1993 were presented to ORNL management in December.

The MMUST issued three principal recommendations based on their evaluation of the information gathered. They are:

- Renew and enhance the ORNL management commitment to matrix management, program managers, and project managers.

- Implement actions to ensure career path parity between the program/project manager family of positions and the technical line manager family of positions across all directorates and divisions.

- Clarify and document program/project manager roles, responsibilities, and authorities.

These principal recommendations were accompanied by subrecommendations and proposed responsibility and authority statements to support implementation of specific actions stemming from the recommendations.

The MMUST recommendations were intended to clarity, to "ture-up," and to communicate the positive features of the existing balanced matrix organization at ORNL, not to generate sweeping change or restructuring of that organization. As so well stated by the team that originally recommended the application of a matrix organization at 
ORNL: "There is reasonable consensus in the management literature on the advantages and disadvantages of the matrix organization concept. It is possible to capitalize on the advantages and solve the problems of the disadvantages by providing acceptable delegated position and management duties to both management lines." The recommendations in this report suggest adjustments that will resolve recent problems related to disadvantages of matrix management and lead to increased benefits from the advantages currently available. 


\section{INTRODUCTION}

Matrix managenient has been an integral part of the Oak Ridge National Laboratory (ORNL) operational approach for over sixteen years. A great deal of the research and development (R\&D) and other work at ORNL is carried out through program and project managers by utilization of eupporting personnel and resources from multiple line organizations.

In 1977 ORNL staff members J. A. Auxier, P. R. Kasten, O. B. Morgan, J. R. Weir, Jr., and M. K. Wilkinson evaluated Ihe Application of Matrix Organization Principles to ORNI!. They concluded:

"There are three primary motivations for utilizing the matrix organizational concept at OPNi.:

The necessity to maintain a large number of highly competent scientific and technical disciplines,

The ability to react to the rapidly changing programmatic needs of the Energy Research and Development Administration (ERDA), and

The need to interact closely with a large number of ERDA program managers.

There is reasonable consensus in the management literature on the advantages and disadvantages of the matrix organization concept. It is possible to capitalize on the advantages and solve the problems of the disadvantages by providing acceptable delegated position and management duties to both management lines."1

Since then, the matrix organizational concept has been used at ORNL, both within division organizations (e.g., the Metals and Ceramics Division) and in broader program offices (e.g., the Office of Environmental Technology Development). The three motivations the team recorded sixteen years ago are still applicable today.

In 1992 the Department of Energy-Oak Ridge Operations Office (DOE-ORO) began comninicating to ORNL perceived concerns about program and project management via letters from R. L. Egli to A. W. Trivelpiece, award fee determination reports, and Performance Evaluation Committee (PEC) reports. These expressions of concern were prompted by a problem in the Radioisotope Thermoelectric Generator Program. Appendix A shows samples of concern statements from 1992 and 1993. 
In May 1993 the ORNL Division/Program/Office Directors Caucus (the Caucus) initiated organization of a "fox team" to evaluate program and project management at ORNL in response to both DOE-ORO concerns and concerns expressed by experienced program and project managers at ORNL. Named the Matrix Management Upgrade Solutions Team (MMUST), it was chartered by the Caucus in June 1993. The principal mission of MMUST was to "identify and recommend improvements in program and project management at ORNL which would lead to resolution of concerns about ORNL performance in this area." Appendix B shows the MMUST charter.

The four-phase approach implemented by MMUST includes:

- Gathering and evaluating information. In this phase interested and involved parties from both ORNL and DOE-ORO were invited to meet with the team and to provide their perspectives on matrix management at ORNL. They were asked to address both positive and negative aspects of existing program and project management and to recommend improvements. Many program managers, predominantly from ORNL but also from the Y-12 Plant, provided information to the team during this phase. Information from these sessions was documented in detailed meeting minutes. The team discussed and evaluated this information as it was received.

- Developing recommendations. When sufficient information had been gathered, the team developed a series of recommendations for improvements to program and project management methods at ORNL. Based on the information gathered, these recommendations are intended to be responsive to both internal and external concerns (see Sect. 2).

- Proposing/promoting recommendations. The recommendations were first presented to the Caucus. After comments and suggestions from the Caucus had been resolved and incorporated, the recommendations were then presented to the ORNL Executive Committee. Comments from the Executive Committee were incorporated, and the recommendations were finalized. Implementation actions for the recommendations were assigned to various organizations with the endorsement and support of both the Caucus and the Executive Committee.

- Supporting implementation of recommendations. The last formal action of the MMUST was the documentation of the recommendations and supporting information in this report. However, the members of the team remain available to support and to assist with implementation of the recommendations as needed. 


\section{EVALUATIONS}

Matrix management is the principal method by which work is carried out at ORNL. An overwhelming majority of the programs and projects carried out at ORNL are well managed and produce results that satisfy customer expectations. While no complex technical activity is trouble-free, program and project managers generally identify, address, and correct problems before deliverables, cost, and schedule are negatively effected. The MMUST conducted a survey of some ORNL programs and projects completed successfully during the past two years. Sixty-one successful programs and projects were identified (see Appendix C).

Also, the MMUST contacted DOE Headquarters program managers to determine their level of satisfaction with work carried out at ORNL. The individuals contacted were those on a list provided to the team by DOE-ORO (E. E. Hoffman) in June 1993. All of those DOE program managers indicated a reasonable level of satisfaction with ORNL work under their programs, and they did not identify any significant problem areas to be addressed. Appendix D shows a summary of the responses from these DOE program managers.

However, ORNL is facing an increasingly competitive future. A combination of highly competent and capable technical staff and program/project managers is essential to future success. In spite of the positive performance discussed above, there are compelling indications of needs for improvement in the implementation of matrix management at ORNL, both in the concerns expressed by DOE-ORO and the information received from some program and project managers at Martin Marietta Energy Systems, Inc.

The MMUST gathered information from program and project managers, as well as other interested parties, over a period of about six months. This information was recorded in detailed meeting minutes that include both verbal discussions and documents (e.g., letters and viewgraphs) provided to the team. Appendix E summarizes the commentary and information received from program/project managers. Team discussions and evaluation of the information received were also recorded in the minutes. The meeting minutes are on file as a backup record for the evaluation results and recommendations in this report.

The principal issues identified by the MMUST evaluation of information gathered are as follows:

- ORNL does not have a defined method for assisting program and project managers with resolution of problems or alerting ORNL management to developing problems requiring attention. Problems in programs or projects that are closely monitored by DOE-ORO (e.g., those related to environmental restoration, waste management, or environment, safety, and 
health) or by other customers can become highly visible before ORNL management has an opportunity to initiate internal corrective action.

- The success or failure of programs and projects at ORNL is dependent on the experience, skills, capability, and personality of individual program/ project managers.

- Program/project managers are held responsible and accountable without defined authority. No formal guidelines or policies are available for program and project manager roles, responsibilities, rights, and authorities.

- Existing organizational structures can prevent or impede effective handling and resolution of interplant problems in programs and projects.

- Matrix management training has not been available for over ten years. Thus our line and program personnel have no common frame of reference for matrix management practices and methods.

- Program and project management is increasingly perceived by our staff as a less desirable career path than technical line management. There is a perceived bias of ORNL management toward technical line organizations compared with programs and projects.

- Program/project manager grade levels are perceived to be nonuniform for similar responsibility levels across ORNL organizations. They appear to be lower in support and service organizations than in R\&D organizations for equivalent responsibilities.

- It is sometimes difficult to attract capable staff to program/project manager assignments. 


\section{RECOMMENDATIONS}

Recommended improvements to matrix management at ORNL have been developed on the basis of the concerns and issues identified in the information gathering and evaluation results described in Sect. 2. Specific recommendations are as follows

- Renew and enhance the ORNL management commitment to matrix management, program managers, and project managers.

Recognize, and provide visible support for, the role of program and project managers as a critical element of ORNL's matrix management system.

- Establish a single point of contact at the Executive Committee level for program/project managers to use when all other routes to resolve a problem have failed. The functions of this point of contact would be:

- to provide guidance and advice to program/project managers for the resolution of matrix problems,

- to support and to assist program/project managers with the resolution of interplant matrix problems, and

- to alert the Executive Committee of emerging program/project problems that need ORNL management attention.

- Establish designated high-level points of contact at ORNL, the Y-12 Plant, and the K-25 Site to enhance the interplant interface and resolution of program/project problems. At ORNL this could be part of the point of contact function described above.

- Reestablish a matrix management training program covering the principles and practices of matrix management. Require that all levels of management, and all staff working with matrix management, complete this training. 
- Implement actions to ensure career path parity between the program/project manager family of positions and the technical line management family of positions across all directorates and divisions.

- Review existing grade level criteria for the program/project manager family of positions and the technical line management family of positions, and the application of these criteria, to ensure that parity exists or to identify corrective actions needed.

- Provide guidance to all line managers on the use of the criteria for determining grade and salary levels for program and project managers.

- Communicate approved grade-level criteria to all interested staff.

- Ensure that the existing criteria are appropriate for the future in light of the evolving role of national laboratories and increasing competition for R\&D budgets.

- Clarify and document program manager roles, responsibilities, and authorities.

- Recommend revision of Appendix A in Energy Systems Policy Procedure ESS-OP-201, Roles and Responsibilities Documentation and Communication, to add a "Program" column with appropriate role, authority, and accountability statements, to the matrix.

Note: Exhibit 3.1 shows proposed statements.

- Modify and expand ORNL Standard Practice Procedure (SPP) X-GP-5, Matrix Support Work Agreements at ORNL, to cover all aspects of matrix management.

- Add program and line management roles, responsibilities, and authorities to SPP X-GP-5.

Note: Exhibit 3.2 shows proposed information.

- Develop and implement improvements in program/project management interfaces and communications. Document guidelines for these improvements in SPP X-GP-5.

Note: Exhibit 3.3 shows proposed information.

- Parity is defined as equal grade level and salary for equivalent responsibility and authority. 


\section{Proposed Changes to}

Energy Systems Policy ES-OP-201 dated September 30, 1991.

Roles and Responsibilities: Documentation and Communication

Appendix A. Descriptions for Role Statements

The following proposed changes to ES-OP-201 are intended (1) to add a column of role statements for the program/project area of responsibility, and (2) to modify the line role statements to reflect the addition of the program/project information.

Role

Line

Delegated through the chain of command to provide, in accordance with policies and procedures, specified products and services both internally and externally.

Program/Project

Delegated through the chain of command to provide, in accordance with policies and procedures, primary interfaces with specified external customers.

\section{Authority}

Line

Sole right (monopoly) to conduct delegated business or to provide delegated products and services. Shared right, with program/project managers, to provide products and services to certain external customers.

Program/Project

Sole right to make commitments for the company with specified external customers/sponsors. Agreement of supporting line organizations must be obtained before such commitments are made. Shared right, with line managers, to provide products and services to specified external customers/sponsors.

Exhibit 3.1. Proposed Changes to Energy Systems Policy ES-OP-201 


\section{Accountability}

Line

For satisfying program, project, customer, and/or sponsor needs and requirements.

\section{Program/Project}

For Energy Systenis' relationship with specified external customers/sponsors. For Energy Systems' performance against customer/sponsor standards.

Exhibit 3.1. Proposed Changes to Energy Systems Policy ES-OP-201, continued... 
Proposed Matrix Management

Roles, Responsibilities, and Authorities

for Standard Practice Procedure X-GP-5

The Oak Ridge National Laboratory (ORNL) operates with a balanced matrix management organization. With this organization much of the work at ORNL is carried out under programs that utilize the technical expertise, resources, and capabilities of the line organizations.

In a balanced matrix organization roles, responsibilities, and authorities are shared by the line and program managers. A clear understanding of those roles, responsibilities, and authorities is essential to the successful performance of this organization. This understanding allows the advantages of the matrix organization to be fully realized and helps to avoid the disadvantages of conflict and confusion between the line and program functions.

Some work and funding may come directly to a line organization from a sponsor. In this case the line manager or principal investigator also serves as a program/project manager and has all of the applicable roles, responsibilities, and authorities described below.

Roles, responsibilities, and authorities are delegated to line and program managers by ORNL and Energy Systems. A general description of those roles, responsibilities, and authorities is listed below. A specific position charter is prepared and approved for each line and program management position delineating the roles, responsibilities, and authorities specific to that position.

\section{Program/Project Managers}

\section{Roles and Responsibilities}

Are the single point of contact between ORNL and a sponsor.

Supervise staff assigned directly to the program/project (contribute to performance evaluations).

Establish program/project objectives, budgets, plans, and performance standards through liaison with the sponsor and supporting line organizations.

Forecast program/project resources requirements. Provide requirement forecasts to the sponsor and supporting line organizations.

Exhibit 3.2. Proposed Matrix Management Roles, Responsibilities, and Authorities 
Obtain required resources and support from line organizations.

Communicate regularly and frequently with line management to remain cognizant of capabilities and to keep them informed of program/project opportunities, sponsor needs, etc.

Define programmatic requirements for work scope, schedule, milestones, deliverables, and quality for supporting line organizations. Obtain line organization input through liaison with line managers and staff.

Ensure that program/project work is carried out according to ORNL and Energy Systems policies and practices. Share this responsibility with line managers.

Negotiate program/project changes (e.g., budget, scope, schedule, milestones) with sponsor. Obtain line organization input through liaison with line managers.

Notify supporting line organizations of program/project changes that could impact line organization work assignments.

Provide program/project status reviews and reports to sponsors. Obtain line organization input for these reviews and report through liaison with line managers.

Provide input to annual performance reviews of line organization personnel assigned to the program/project.

Administer Environmental, Safety, and Health (ES\&H) and Quality programs for the program/project.

Manage overall program/project performance including budget and cost, schedules, milestones, deliverables, and quality.

Plan for, and requests funding for, line organization closeout costs associated with program/project for the completion or termination.

\section{Authority}

Define program/project organization structure.

Exhibit 3.2. Proposed Matrix Management Roles, Responsibilities, and Authorities, continued... 
Allocate and reallocate program budgets.

Contribute to program/project staff performance evaluations according to Energy Systems criteria and requirements.

Approve personnel selected for assignment to the program/project by line organizations.

Approve objectives, schedules, milestones, technical specifications, and quality assurance plans for line organization work assignments.

Approve program/project deliverables provided by line organizations.

Stop work if program/project performance requirements (e.g., technical specifications, hudgets, schedules, and quality) are not being met. Coordinate stop work actions with responsible line managers.

\section{Line Managers}

\section{Roles and Responsibilities}

Supervise the line organization staff (including hiring, performance evaluation, salary actions, etc.).

Manage facilities utilized by the line organization.

Forecast line organization staff, equipment, and facility requirements.

Administer ES\&H and Quality programs for the line organization.

Provide technical support and services to programs/projects.

Define program/project specific work assignments for line organization personnel assigned to a program/project. This is usually done through liaison with program/project managers.

Define requirements for task-specific work scope, schedule, milestones, deliverables, and quality for line organization support to programs/projects. Obtain program/project requirements through liaison with program/project managers.

Ensure that commitment of line organization resources (staff and facilities) to programs/projects is balanced and can support program/project needs.

Exhibit 3.2 Proposed Matrix Management Roles, Responsibilities, and Authorities, continued... 
Notify program/project managers of changes that could affect program/project budgets, schedules, deliverables, or other requirements.

Ensure that line organization work is carried out according to ORNL and Energy Systems policies and practices. Share this responsibility with program/project managers.

Accept program/project manager input to line staff performance reviews and integrate this information into performance evaluations.

Maintain active interfaces with program/project managers and provide support for development of new programs/projects.

Recommend action alternatives when line organization resources are not available to meet program/project objectives and commitments.

Define closeout costs for staff reassignments and equipment/facility restoration associated with program/project completion or termination.

\section{Authority}

Define and delegates responsibilities and work assignments for the line organization staff.

Determine line organization staff performance ratings, grade levels, and salary levels according to Energy Systems criteria and requirements.

Allocate and reallocate line organization resources (i.e., staff, equipment, and facilities) to meet commitments.

Approve line organization deliverables before they are transmitted to a program/project.

Hire staff and obtain equipment/facilities as needed to meet line organization forecast requirements.

Stop work being performed by the line organization if performance requirements (e.g., technical specifications, budgets, schedules, and quality) are not being met. Coordinate stop work actions with responsible program/project manager.

Exhibit 3.2. Proposed Matrix Management Roles, Responsibilities, and Authorities, continued... 


\section{PROPOSED MATRIX MANAGEMENT GUIDELINES}

The Oak Ridge National Laboratory has a balanced matrix management organization. In a balanced matrix the line and program/project managers share responsibility and authority, (i.e., neither the program/project managers nor the line managers have sole responsibility for all aspects of the planning and execution of a program or project). Those responsibilities and authorities are described in Exhibits 3.1 and 3.2.

Success in a climate of shared responsibility and authority requires teamwork and close cooperation between the line and program/project organizations. Both program/project and line managers must provide the leadership and guidance needed to establish teamwork and cooperation in program/project development, proposal preparation, work plan development, and in the execution of the work.

The guidelines listed below are intended to help both program/project and line organization personnel to work more effectively in the matrix organization:

- Effective and efficient working relationships between ORNL divisions and programs, and between Energy Systems business units as well, are important to the success of ORNL and Energy Systems. Critical components of these relationships are clear communications and acceptance of roles and responsibilities.

- Supporting line organizations should be involved in the development and definition of a program or project as early as possible.

- Program/project plans and resource requirements should be developed by teams of program/project and line organization staff members. If possible, these teams should include the individuals who will execute the work planned. Agreement between program/project managers and supporting line organizations must be reached before commitments are made to a customer or sponsor.

- A uniform program/project description defining significant program/project parameters should be communicated to all involved personnel early in the planning process. This description should be updated periodically as the program/project evolves. The description should include:

- $\quad$ program/project title;

- $\quad$ summary program/project description;

- budget, schedule, and major milestones;

- communication system (meeting, reviews, and reports); and

Exhibit 3.3. Proposed Matrix Management Guidelines 
- the organizations and personnel involved in the program/project, including at least two layers of supervision or management in each organization (this should include telephone numbers and electronic mail identifiers).

- Program/project requirements for technical support should be documented clearly and completely and provided to all supporting line organizations. If possible, line organization personnel should be involved in the definition of these requirements. These requirements should include ES\&H requirements and quality criteria.

- Detailed work agreement between the program/project and each supporting line organization should be used to define the work to be performed, including roles and responsibilities, budgets, schedule, milestones, work scope, deliverables, and technical criteria. These should be developed jointly between the two organizations if possible. Work agreements should be signed by the responsible program/project and line managers.

- Program/project reviews should be held at regular intervals. These reviews should focus on identifying problems, or potential problems, and identifying solutions. If possible, the sponsor and ORNL management should be represented in these reviews. It is important to avoid finger pointing, blame, and recriminations (the kill the messenger syndrome) in these reviews. Instead, they should be an opportunity for open, constructive communication and teamwork.

- When problems are identified, teams of the staff most involved with that aspect of the program/project should be asked to develop and to recommend solutions. Whenever possible, the recommendations of these teams should be implemented.

- Program/project managers should identify the management lines for each organization involved in the program/project. Chains of command, responsibilities, and points of contact should be determined. This is particularly important when organizations from several plant sites are involved. The program/project manager should know what level of management to involve for help when problems cannot be resolved at the program/project level.

- Program/project managers should report evolving significant problems to ORNL management before the problems become critical issues with customers. The problems should always be resolved within our organization before external customer personnel feel compelled to step in.

Exhibit 3.3. Proposedl Matrix Management Guidelines, continued... 


\section{REFERENCE}

1. J. R. Weir, Jr., et al., Application of Matrix Organization Principles to ORNL, ORNL pamphlet, Union Carbide Corporation Nuclear Division, Oak Ridge National Laboratory, 1977. 


\section{GLOSSARY}

Project

A major endeavor, which rnay or may not be one of several activities within a program, with a singular objective and firmly scheduled beginning and end dates.

Program

An organized set of activities directed toward a common purpose, objective, or goal. A program may include a number of projects.

Project manager

An individual delegated. the responsibility, authority, and accountability for managing a specified project.

Program manager

An individual delegated the responsibility, authority, and accountability for managing a specified program.

Program/Project

A term designating the use of the terms program and project in the either/or context (i.e., either a program or a project). 
Appendix A

STATEMENTS OF CONCERN 


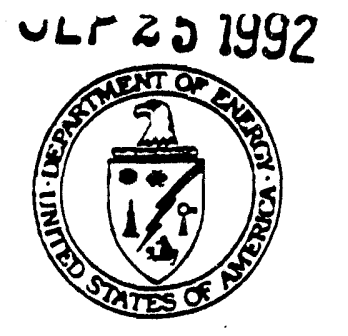

SEP $\div 8982$

\section{Department of Energy \\ Oak Ridge Field Office \\ P.O. $80 \times 2001$ \\ Oak Ridge. Tennessee 37831- 8600}

September 23, 1992

Dr. Alvin W. Trivelpiece, Director

Oak Ridge National Laboratory

Martin Marietta Energy Systems, Inc.

Post Office Box 2008

Oak Ridge, Tennessee 37831-6255

Dear Dr. Trivelpiece:

\section{AWARD FEE BOARD ISSUES AND CONCERNS}

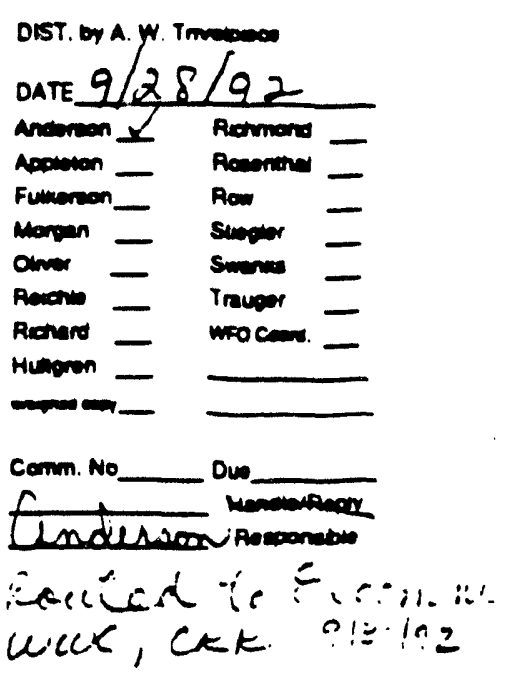

This is my third in a planned series of monthly letters to you about my observations and perceptiors on the Laboratory's performance. As mentioned in my first letter of July 14, 1992, I want to concentrate on those topics where improvement could be reflected positively as far as overall performance is concerned. This month's input is in the following areas:

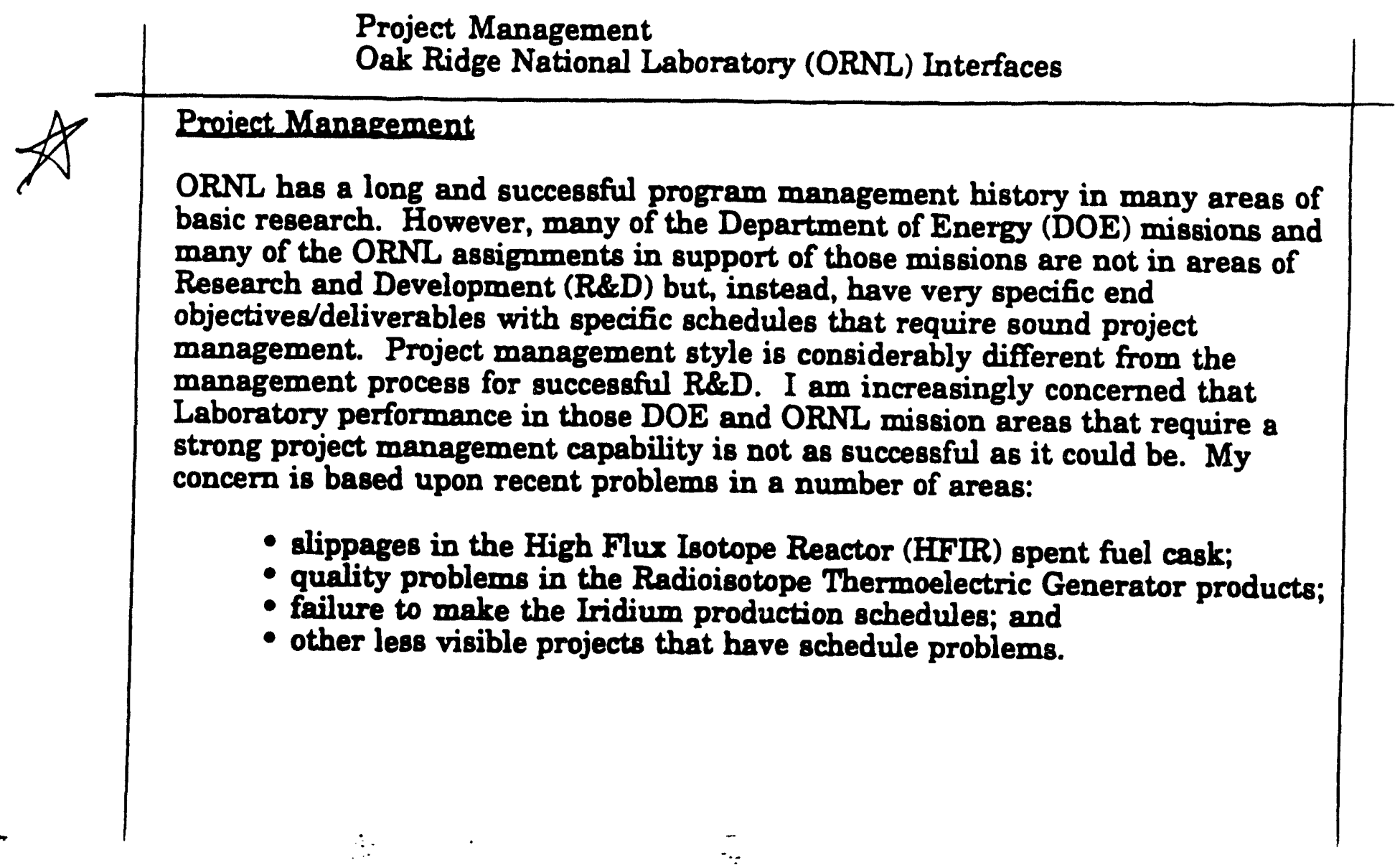


As pointed out in the Burns and Roe assessment done two years ago, ORNL's consensus management style and way of doing business "is so unstructured and undisciplined that productive management direction to meet objectives does not occur." I believe it timely for ORNL management to undertake a very serious internal review of this matter.

\section{ORNL Interfaces}

During the recently completed multi-functional appraisal at ORNL, one of the areas examined was the interface between Line and Support organizations. When the team conducted a vertical slice review on pressure relief valves, they discovered a number of problems involving inadequate communications across the Line/Support interface that could potentially degrade safety systems at the Laboratory. There appears to be no consistent standard and the Line determines when and if any support is necessary. In times of budgetary pressures, this probably means less than adequate support is being requested in the areas of Health Physics, Industrial Hygiene, Industrial Safety, and Maintenance. There will most likely be budgetary pressures in the near future that will put stress on our ability to meet our goals in a timely manner. However, we must be careful that Safety and Health are not compromised in the process of managing the limited resources that are available. Part of good management is ensuring that good Line/Support interfaces exist so that the deficiencies noted during the recent appraisal are not repeated.

I will be happy to discuss these matters with you further.

Sincerely,

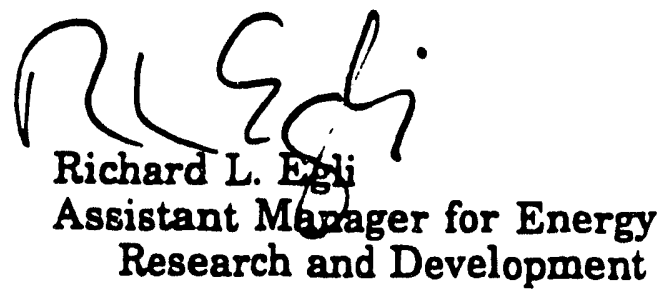

cc:

Joe La Grone, M-1, OR

Ted Marquess, FM-70, OR

Ronald Hultgren, ER-10, OR

William Manning, ER-10, OR

92.7594 


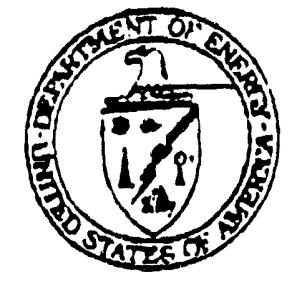

\section{Department of Energy \\ Oak Ridge Field Office \\ P.O. Box 2001}

Osk Ridge. Tennesser 37839-

November 5, 1992

Dr. Alvin W. Trivelpiece, Director

Dak Ridge National Laboratory

Martin Martetta Energy Systems. Ine.

P. O. Box 2008

Oak Ridge, Tennessee 37831-6255

Dear Dr. Trtvelplece:

AMARD FEE DOARO ISSUES AND CONCERNS
H. R. YEOK

Jun $5: 33$

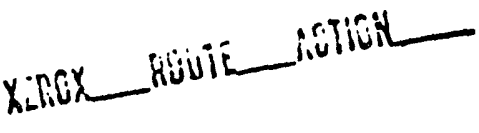

Thls is my ruurbll III a plannod sorfes of monthly lottore to srou about my observations and perceptions on the Laboratory's performance. As mentioned in my first letter of July 14, 1992, I want to concentrate on those toples for improvement in overali performance. This month's input is in the following areas:

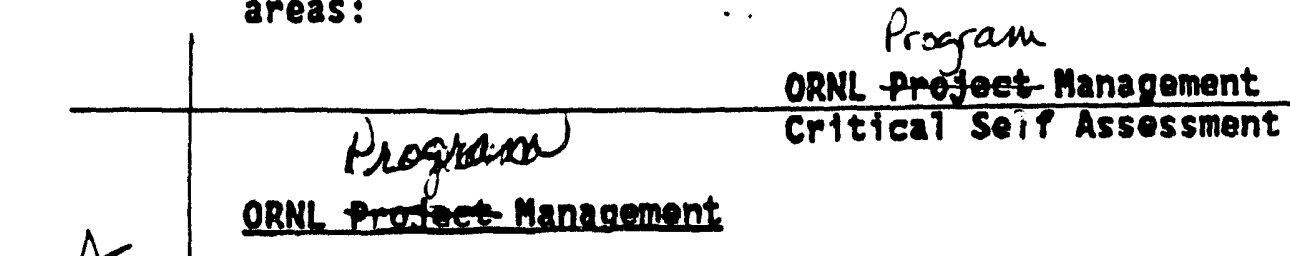

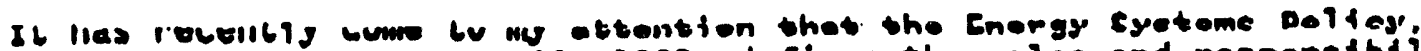
ES-0P-200, dated January 10, 2992, defines the roles and responsibitities of ifne managers and coordinators, but does not mention the program manager role. ORNL is organized by divisions, for the most part by disciplines, with program

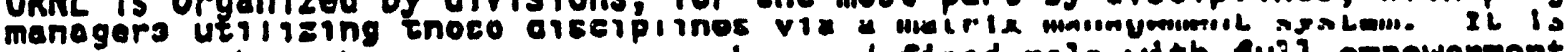
Impuilailt thet tho program managor has a dofinod molo with flit ompowarmont that coincides with the responsibility to accomplish a stated mission.

ORNL program managers have insufficlent authority and empowerment over those Dortions of tneir programs impiomented at ullur Eivoryy systoms Dusinass Unit facilities. This is very much iliustracoo oy trie uverail raliure ur management ruspuils iblilty within the Radiolsotopo Thormooloctric Ganerator (RTG) prografn. UKWi program managers tiave fittier thrited or no authority and do not have direct authority over the organizations performing thefr work. It is important that everyono involved in a project solve problens and assess progroce ac toem. It te ien molimial to hava an amnnwarad individual responsibie for muriayling line team's offorts to meat doliveries on sohodule within cost bounds.

The Laboratory has demonstrated that such teams have been formed and have shown romarkable success. Two examples from widely differing areas are the success in moeting cructal milestones of the regulatory agreement for stack monitoring and in developing the ammunition delivery system for the Army. those suecessful practices snoula de used across ine Lavuracury rur prujects. 


\section{Critical Self Assessment}

Critical self assessment was discussed at the first PEC meeting as one of the several areas needing emphasts during this award fee period. Self assessment was ctted as less than adequate in the recent Fy92-2 appratsal of the Laboratomy. Nelther the monthly nor the semi-annual assessment cited defictencies not already clted by OOE; management shortcomings were not acknowledged; project management problems and root causes were not addressed; lacks line-management input for safety and health; and the assessment lacks balance in many areas by noticeably leaving out deficienctes where they obviousiy have occurred and been documented by DOE. The Performance Evaluation plan states: "The contractor should be prepared to discuss the results of 1ts self assessment process at the monthly PEC moetings." Your input in the monthiy PEC meetings ropresents the ORNL self-assessment at that time. It is imporative the ORNL input represents a eritical self-assessment of activities, whether constdered achievements or deficlencies.

I will be happy to discuss these matters with you further.

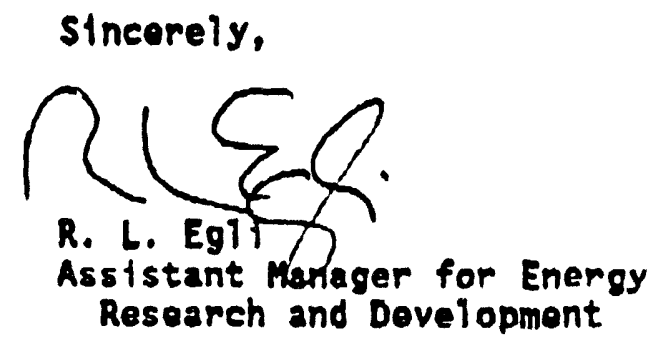

ce:

Joe La Grone, $M-1$

Ted Marquess, FM-70

B111 Manning, ER-10

Ron Hultgren, ER-10 


\section{Department of Energy}

Field Office, Oak Ridge

P.O. Box 2001

Oak Ridge, Tennessee 37831- 8793

November 30, 1992

Mr. Clyde C. Hopkins, President

Martin Marietta Energy Systems, Inc.

Post Office Box 2009

Oak Ridge, Tennessee 37831-8001

Dear Mr. Hopkins:

AWARD FEE DETERHINATION FOR MARTIN MARIETTA ENERGY SYSTEMS, INC., CONTRACT NO. DE-ACO5-840R21400, SECOND HALF FY 1992

I have completed my assessment of Martin Marietta Energy Systems, Inc. (Energy Systems), performance for the evaluation period April 1, 1992, through September 30, 1992, and have made the following determination.

\begin{tabular}{|c|c|c|}
\hline BUSINESS UNIT & RATING & AWARD FEE \\
\hline Weapons & Good & $\$ 2,574,600$ \\
\hline Laboratory & Satisfactory & $1,273,050$ \\
\hline Appl ied Technology & Satisfactory & 1.197 .360 \\
\hline TOTAL & & $\$ 5,045,010$ \\
\hline
\end{tabular}

Should you wish to request reconsideration of this determination, the procedure contained in Part I of the Award Fee Determination Plan should be followed.

Energy Systems performance was evaluated in the management and operation of each of the business units. In arriving at my determination, I considerad information obtained from the Award Fee Board, Performance Evaluation Committees' (PEC) reports, cognizant Headquarters offices, as well as Energy Systems comments on the PEC reports, Energy Systems self-assessment reports, and my own observations.

The evaluation process identified noteworthy achievements during the period as well as problem areas that require your attention. Sumarized below, by business unit, are the achievements and deficiencies that formed the basis for my determination. 


\section{Weapons Business Unit}

The $Y-12$ Plant has continued to be responsive to mission changes. The first phase in the dismantlement of the $B 33$ weapons system was completed on schedule using a new procedure which eliminated the generation of new mixed Resource Conservation and Recovery Act (RCRA) waste. The new process resulted in a cycle-time reduction in excess of 400 percent. Emphasis in planning for the Clean Air Act rulemaking process has resulted in the development of an implementation plan and a Stratospheric Ozone Protection Plan. $Y-12$ is in the process of finalizing recommendations for source categories to be considered for the Environmental Protection Agency's (EPA) Early Reduction Program for Hazardous Air Pollutants. A Safeguards and Security Readiness Review conducted by Headquarters Office of Security Evaluations rated all reviewed areas Satisfactory, which is the highest rating that can be awarded. Y-12's commitment toward compliance with National Pollutant Discharge El imination System (NPDES) regulations is evidenced by the 50 percent reduction in noncompliances. $Y-12$ completed corrective action commitments associated with the Federal Facilities Compliance Agreement (FFCA) for compliance with the National Emission Standards for Hazardous Air Pollutants (NESHAP) for Radionuclides. As a result of $Y-12^{\prime}$ 's outstanding performance and efforts to fully accommodate and communicate openly, EPA representatives acknowledged that working relationships with DOE have significantly improved. Substantial progress has been made on the Safety Analysis Report Upgrade Program, and all remaining Phase IA Operational Safety Requirements were completed.

Additionally, progress continues toward compliance with OSKIA. $Y-12$ held the "Beyond the Fence" Forum which highlighted Y-12's new technology transfer mission. $Y-12$ and the Oak Ridge National Laboratory (ORNL) have jointly developed and submitted over 80 technology transfer summary-level proposals and 25 detailed proposals. Y-12 facilitated a Cycle-Time Reduction study to streaml ine the National Environmental Policy Act Categorical Exclusion approval process and decreased its portion of the process by 57 percent. The outplacement program to mitigate the impacts of the reduction in force was outstanding. Preparation, coordination, and response to the large number of audits, appraisals, and visits by the Defense Nuclear Facility Safety Board staff and State and Federal regulatory agencies were very good. Approximately 14,000 open OSHA findings have been risk-ranked utilizing the Risk Assessment Code of the proposed DOE Order 5483.XX.

$Y-12$ has made significant improvements in the environmental area; however, serious problems continue to exist with line-management's implementation of Safety and Health programs, especially in radiation protection and contamination control and Conduct of Facility Operations programs. The number, severity, and frequency of these deficiencies raise concerns about line management's commitment to a safe and healthy work environment. There remain significant concerns with the $Y-12$ RCRA inspection program. Inadequate technical detail during the inspection program and inadequate data validation during permit preparation have resulted in inconsistent application of RCRA practices within the Plant. $Y-12$ did not complete the milestone related to the Radioisotope Thermoelectric Generator project. Communications and teamwork with the ORNL materials specialists need to improve. Several final 


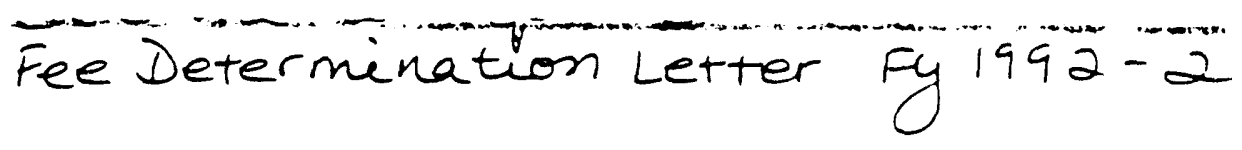

Mr. Clyde C. Hopkins

$-3-$

November 30,1992

occurrence reports sent to DOE contained inadequate descriptions and root cause analysis. All exits from radiological and contamination areas are not equipped with personnel monitoring equipment. This has been mentioned in previous award fee reports. Problems have developed in the definition of scope for Safety and Health (S\&H) projects. This is evidenced by the design for Health and Safety Readiness Review items being several months late on the Air and Water Pollution Control Facilities and the 2-month delay in the Air and Water Project strategy to complete the B-1 Wing. Emphasis needs to be placed on the $Y-12$ Quality Program due to the error in the shipment made to a commercial reactor customer and the very low rating assigned by the Technical Safety Appraisal (TSA). Corrective action status updates and closure continue to be deficient as evidenced by the quarterly status updates for the 1986 and 1988 TSAs, the 1990 DOE multidisciplinary review, and the seven Tiger Team corrective actions which remain open. Adequate status tracking is not achievable with the input currently being supplied.

\section{Laboratory Business Unit}

* ORNL continues to achieve excellence in many areas of Research and Development (R\&D) as noted through surveys of HQ program sponsors. For example, ORNL won four R\&D 100 Awards for 1992 from R\&D Magazine for development of a $\mathrm{Ch}$ iorofluorocarbon-Hydrofluorocarbon Ratiometer, development of a surfaceenhanced optical data storage compact disk, creation of the hard-surface polymers by ion-beam techniques, and development of computer technology to help decipher the human genome. ORNL researchers demonstrated in-situ soil treatment technologies at the Portsmouth Gaseous Diffusion Plant and have continued to make progress in developing advanced ion aluminide alloys. Good progress has been made on the Supercomputing Program with the acquisition of new hardware/software.

Through the Office of Science Education and External Relations, ORNL continues to work successfully toward meeting the educational goals of SEN-23-90 such as partnerships with local schools and research programs with Minority Educational Institutions. The High Flux Isotope Reactor (HFIR) and the Tower Shielding Reactor have continued to achieve high performance while maintaining safe operations. The Advanced Neutron Source Program has been managed very effectively with excellent project documentation. The Office of Technology Transfer continues its outstanding leadership nationally in assisting other DOE sites and states in their technology transfer development while executing 34 new Cooperative Research and Development Agreements in Oak Ridge. ORNL's Environmental Management program is proactive, exceptionally well managed, and continues to improve. Examples include the highly regarded NESHAP Program and ambient air/stack monitoring programs. ORNL was aggressive in preparing an excellent S\&H 5-Year Plan. Accomplishments in operations included excellent waste minimization and nuclear materials management programs.

S\&H deficiencies continue to be noted during appraisals at ORNL. Some of these deficiencies are very serious and reflect lack of leadership on the part of top Laboratory management. Management should consider Laboratory S\&H at 
least as important as Laboratory R\&D. Management systems to raise and resolve issues and determine root causes are not effective. The end results have been significant deficiencies in lockout/tagout, use of perchloric acid contaminated hoods, and electrical hazards. Health physics practices have been inconsistent. The recurring nature of many of these problems and the inability of the Laboratory to self-identify them is a direct result of lack of attention from top management. ORNL management needs to continue efforts to improve OSHA compliance programs, specifically with regard to planning and implementation. Another area of serious deficiency involves the management of projects. ORNL has not demonstrated the ability to organize and carry out assigned tasks outside of a "consensus" atmosphere. Examples include: lack of a proactive approach for the HFIR Spent Fuel Cask regarding the Safety Analysis Report for Packaging and the pursuing of alternate cask sources; large numbers of cracked and contaminated parts in the Radioisotope Thermoelectric Generator project due to lack of integration and oversight of $Y-12$ production; and slipping iridium production schedules resulting from lack of program management attention. Despite some progress by the contractor.

considerable DOE attention and oversight of hot cell operations has been required for problems such as Facility Radiation and Contamination Alarm Systems failures, radiation streaming, and contamination occurrences. Although progress is being made in the closeout of many Tiger Team findings, improvements are still necessary in the overall program for tracking and closing corrective actions. Improvements are al so needed in communications and cooperation relative to performance criteria development and implementation.

\section{Applied Technology Business Unit}

Revision two of the Corrective Action Plan for the final K-25 Tiger Team Assessment report was submitted to the DOE $K-25$ Site Office in the required 4 weeks. Few revisions to the document were necessary prior to submittal. The K-25 Plant Manager's Facility Excellence Program has achieved substantial results through ownership, peer review, and high visibility of results. Substantive activities have occurred during the period to ensure compliance with the Americans with Disabilities Act (ADA). The ADA Accessibility Committee worked with line management to identify barriers for corrective action. K-25's Adopt-a-School Program continues to be actively involved with Lonsdale Elementary School and Cherokee Middle School. The K-25 Site began a comprehensive assessment of individual personnel clearance needs. As of the end of the appraisal period, most of the assessment work was completed, but data on clearance changes was not yet published. The effort put forth by the K-25 Site Fire Protection Department to correct previousiy identified deficiencies and to revise/develop procedures is commendabie. The OSHA Upgrades program at the K-25 Site has developed into a more structured activity, although work is still required to inform managers of the risk rankings of the deficiencies they must correct. Outstanding efforts on the negotiation of the $K-25$ Site NPDES permit resulted in a monitoring program 
that should decrease costs for sampling and capital improvements. Central Waste Management Division (CWMD) provided significant support in the negotiations of the FFCA for mixed Land Disposal Restrictions (LDR) wastes stored at the Oak Ridge facilities. The Mixed Waste Storage Expansion Project achieved its goal of modifying nine $k-25$ vaults 1 month early. The enlargement of the scope of the project to include two additional vaults, combined with staying within cost, is noteworthy. Deployment of the Direct Sampling Ion Trap Mass Spectrometer equipment for use at the Savannah River Site represents a major achievement in demonstrating the ability to successfully transfer technology from the laboratory to the field. The Portsmouth Environmental Restoration Program showed initiative in the implementation of the Geoprobe and Hydro Punch sampling methodology for the Quadrant III Remedial Investigation effort. Energy Systems Community Relations activities continue to provide excellent support to the Environmental Restoration Program as demonstrated by the workshops conducted for the employees of the firms located in the industrial park across from Bethel Valley Road at Kerr Hollow Quarry. The transfer of the solidified sludge drums from the K-25 Vaults to the K-31 Building was completed ahead of schedule. Transfer of the stabilized sludge drums from the yard continues to be ahead of schedule. The Hazardous Waste Remedial Actions Program has continued to search out more efficient clean-up methods to satisfy its customers. Issuance of the Energy Systems quality policy, that was revised to incorporate DOE Order $5700.6 \mathrm{C}$ concepts and emphasize line responsibility for quality, is a notable achievement. Energy Systems support in working with outside regulatory agencies has been notable across the business unit.

Operational activities at the Toxic Substance Control Act (TSCA) Incinerator continue to be plagued with Conduct of Operations deficiencies as demonstrated by a number of incidents during the period. In addition, TSCA Incinerator operating costs continue to be a concern. Action by Energy Systems to reduce the unit cost for mixed-waste incineration is needed. Lack of timely management response to rising K-25 Site service rates in the Technical and Maintenance Divisions resulted in significant cost variances which had a detrimental impact on plant programs. Waste management corrective activities at the $Y-12$ Plant have suffered from a lack of attention and progress with available funding not utilized. Corrective action reports in response to DOE Waste Management Division surveillances have not been submitted in a timely manner. Three of six have been late, two at the $\gamma-12$ Plant and one at ORNL. Planning between the Office of Technology Transfer and the Technical Program Manager regarding potential Cooperative Research and Development Agreements has beer poorly coordinated. Data quality and quality management deficiencies have been identified within the Environmental Restoration Program. This is a situation which needs immediate management attention and resolution. Energy Systems original Environmental Restoration midyear reallocation request was deficient due to inadequate review times of financial information and poor justifications for additional funding requests for many Activity Data Sheets. Continual difficulty in controlling expenditures and commitments in the Work 
for Others program is a troubling deficiency. This issue has arisen during the last three evaluation periods. Following receipt of the March 1992 Energy Systems Corrective Action Plan (CAP) to address issues raised by DOE in the laboratory analytical and field sampling Quality Assurance/Quality Control (QA/QC) activities, DOE notified Energy Systems of concerns with the PIan in May 1992. Specific DOE issues raised in September 1991 regarding laboratory analytical and field sampling QA/QC activities were not in the March 1992 CAP, and the multiple committees established to address deficiencies were not focused enough on these issues. Energy Systems rating of "conditional" by the U.S. Department of Transportation (DOT) is disturbing as it indicates that Energy Systems does not have adequate safety management controls in place to ensure compliance with DOT Federal Motor Carrier Safety Regulations.

As in previous periods, the award fee self-assessment reports lack the necessary aspects of a critical self-evaluation. Ample time is allowed by DOE for issuance of the self-assessment reports yet they continue to be lacking in identification and ownership of deficiencies. Your personal attention and that of your senior management is needed to improve the quality and objectivity of the self-assessment reports.

The Oak Ridge Environmental Advisory Committee to Energy Systems continued to be active during the latest award fee period. I look forward to seeing the Committee report that is currently in preparation.

We again offer you and/or your staff members the opportunity to meet with our senior managers and their staff members to discuss the basis for the ratings Energy Systems received. Hopefully, these discussions will clarify any areas of misunderstanding.

I have instructed Contracting Officer's Representatives to begin working with their respective Energy Systems counterparts to correct identified deficiencies, and I look forward to discussing progress during our weekly meetings.

Sincerely,

FM-731: Taylor

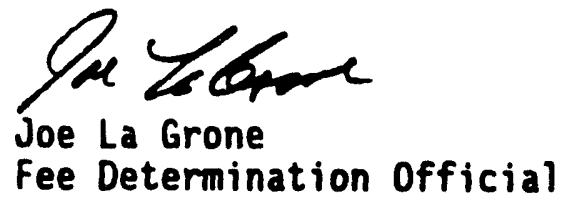




\section{DEPARTMENT OF ENERGY OAK RIDGE FIELD OFFICE}

\section{Performance Evaluation Committee Report}

for

\section{- Martin Marietta} Energy Systems, Inc.

\section{Laboratory Business Unit}

Contract No. DE-AC05-84OR21400

Evaluation Period:

April 1, 1992 - September 30, 1992 


\section{EXECUTIVE SUMMARY}

\section{A. Laboratory Management}

+ ORNL has initiated formal strategic planning to chart the future missions and technology R\&D emphasis arens of the Laboiatory.

- Laboratory Management has not demonstrated the necessary leadership in Safety, Health, and Quality.

- Management systems for raising and resolving S\&H issues are often ineffective and inefficient.

- The Laboratory has not implemented effective systems to address numerous ES\&H findings and root cause analyses.

- Laboratory responsiveness and initiative are lacking for the HFIR Spent Fuel Cask Program.

- Serious quality problems have occurred in the production of parts for the National Radioisotope Thermoelectric Generator Program.

- Iridium production has not met expectations and has insufficient program management attention.

- The Self Assessment report is not a critical self-evaluation:

1. Almost all deficiencies alieady cited by DOE.

2. Most R\&D sccomplishments recognized.

3. Most Environment, Safety, and Health achievements recognized, although some are overstated.

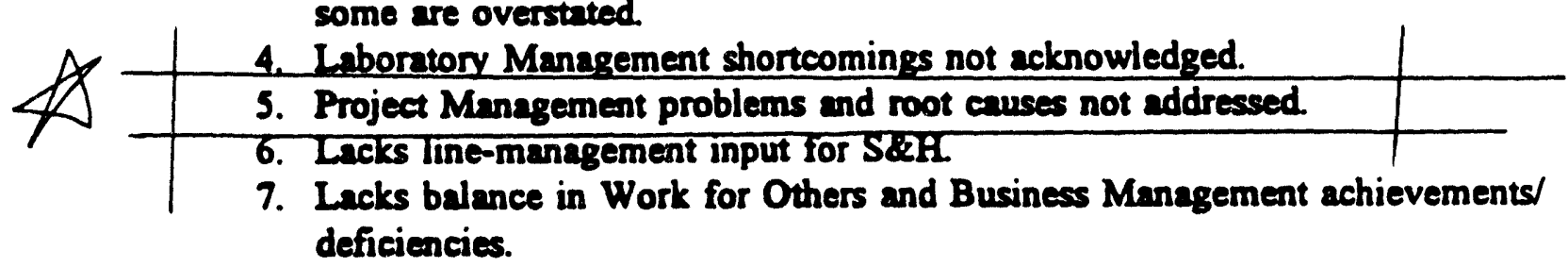

B. Conduct of Research and Development (R\&D)

+ ORNL won four R\&D 100 Awards for 1992 from R\&D magaine:

1. Development of a Chlorofluorocarbon-Hydrofluorocarbon Ratiometer.

2. Development of a surface-enhanced optical data storage compact disk. 
April 13, 1993

Executive Committee

Technical Assistants

W. R. Martin

C. R. Richmond

\section{Performance Evaluation Committee (PEC) Reports for FY 1993-1}

The attached PEC report should be reviewed for factual Jiscrepancies and major judgmental differences. It is important to read the entire report as references to specific directorates are made throughout the document. Any noted problems should be promptly discussed with the appropriate OR counterpart and also submitted to me. It is important to provide OR with accurate information at this early stage in our performance evaluation; any problems with the PEC reports will also be formally documented via the Energy Systems Contracts Division.

The ORNL PEC will brief the OR Award Fee Board on ths report on Monday, April 19, 1993. If you disagree on any substantive issues in the PEC report, $t$ is to the Laboratory's advantage to inform the PEC chair before the briefing. Unfortunately, this means I need to receive your preliminary comments by cob, Thursday, April 15, 1993. I need your formally stated comments regarding any differences by cob, Wednesday, April 21, 1993. The Energy Systems Contracts Division will consolidate our comments with those from the other business units for the direct formal transmittal to the Award Fee Board. Please send your comments to me via electronic mail (NLG) or facsimile (6-6183). If you find the report to be acceptable as written, please convey that message to me as well.

According to the PEC's evaluation as stated in this report, the Laboratory Business Unit has achieved an overall satisfactory level of performance in FY 1993-1. As compared to FY 1992 2. improvement has been reported in Laboratory Management, MMES Technology Transfer, and Research Reactors. The comments contained in the "Sponsor Satisfaction with R\&D" section are direct quotes from the Sponsor Satisfaction Survey responses received from DOE. HO.

I apologize for the very short turnaround time on this important task. Thanks for your cooperation.

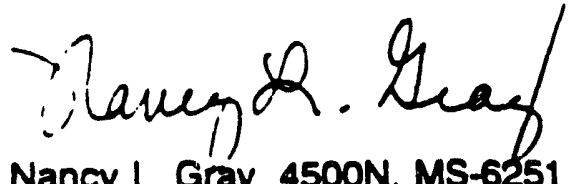

Nancy L. Gray, 4500N, MS-6251 (6-9479)

Attachment

c/att: File - RC 


\section{Prefoce}

This document contains an assessment by the Laboratory Business Unit (LBU) Performance Evaluation Committee (PEC) of Martin Marietta Energy Systems, Inc. (Energy Systems) performance over the period October 1, 1992, through March 31, 1993. The evaluation is based on objectives and criteria contained in the Performance Evaluation Plan dated September 1, 1992, for the same period of performance and was developed utilizing information from daily interactions, appraisals, audits, evaluation of progress and technical reports, and input from program sponsors. Every effort has been made to share this information with the contractor during the evaluation period. Not every finding from every appraisal report was presented at PEC meetings but was referenced at those meetings and could be included in this report.

\section{Submitted by,}

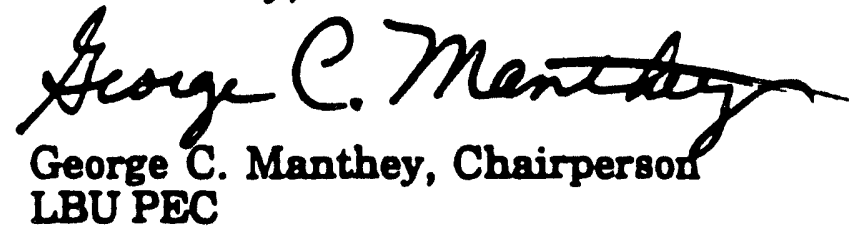

PEC Members:

G. L. Beckner

L. E. Brock

D. L. Buhaly

B. Cox

M. J. Kass

C. L. Matthews

R. M. Poteat*

M. S. Robinson

B. S. Willis

H. J. Wunschel

cc:

R. O. Hultgren

T. M. Jelinek

W. F. Manning

P. F. Taylor**

*Chairperson, Technology Transfer Subcommittee

* Executive Secretary, Award Fee Board 


\section{TABLE OF CONIENTS}

I. CONCLUSIONS $\ldots \ldots \ldots \ldots \ldots \ldots \ldots \ldots \ldots \ldots \ldots \ldots$

II. EXECUTIVE SUMMMARY $\ldots \ldots \ldots \ldots \ldots \ldots \ldots \ldots \ldots \ldots \ldots$

III. COMMENTARY $\ldots \ldots \ldots \ldots \ldots \ldots \ldots \ldots \ldots \ldots \ldots \ldots$. 9

A. Laboratory Management $\ldots \ldots \ldots \ldots \ldots \ldots \ldots \ldots \ldots \ldots$

B. Sponsor Satisfaction with R\&E $\ldots \ldots \ldots \ldots \ldots \ldots \ldots \ldots \ldots \ldots$

1. Office of Energy Research (ER) .................11

2. Assistant Secretary for Nuclear EnerEy (NE) $\ldots \ldots \ldots \ldots 20$

3. Assistant Secretary for Fossil Energy $\ldots \ldots \ldots \ldots \ldots \ldots 24$

4. Assistant Secretary for Conservation and Renewable Energy (CE) ......................... 24

5. Office of New Production Reactors (NPR) . ..........36

6. Other DOE Sponsors $\ldots \ldots \ldots \ldots \ldots \ldots \ldots \ldots \ldots \ldots, 36$

C. Program/Line Management Operations $\ldots \ldots \ldots \ldots \ldots \ldots . .39$

1. R\&D-Related Programs $\ldots \ldots \ldots \ldots \ldots \ldots \ldots \ldots \ldots$. 39

2. R\&:D-Related Initiatives ................. 45

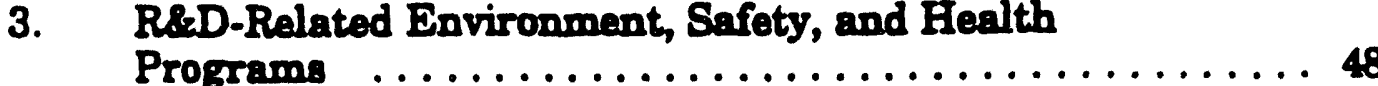

4. ORNL Technology Transfer $\ldots \ldots \ldots \ldots \ldots \ldots \ldots \ldots, 51$

D. Technology Transfer (MMEs-Wide) $\ldots \ldots \ldots \ldots \ldots \ldots \ldots \ldots 52$

E. Research Reactors Operations $\ldots \ldots \ldots \ldots \ldots \ldots \ldots \ldots \ldots, 54$

F. Environmental Management (ORNL-Wide) .............56

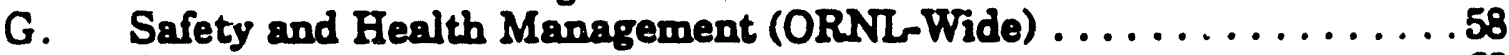

H. Operations $\ldots \ldots \ldots \ldots \ldots \ldots \ldots \ldots \ldots \ldots \ldots \ldots \ldots, \ldots \ldots$

1. Waste Minimization ....................63

2. Facilities .........................64

3. Business Management ..................66 66

4. Laboratory Protection $\ldots \ldots \ldots \ldots \ldots \ldots \ldots \ldots \ldots, 68$

5. Human Resources $\ldots \ldots \ldots \ldots \ldots \ldots \ldots \ldots \ldots \ldots$

6. Health Services $\ldots \ldots \ldots \ldots \ldots \ldots \ldots \ldots \ldots \ldots \ldots \ldots$

1. Headquarters/Customer Survey Results .............. 73

J. Functional Appraisals $\ldots \ldots \ldots \ldots \ldots \ldots \ldots \ldots \ldots \ldots \ldots \ldots$

APPENDIX: ACRONYMS $\ldots \ldots \ldots \ldots \ldots \ldots \ldots \ldots \ldots \ldots \ldots$

ii 


\section{CONCLUSIONS}

Energy Systems performance for the LBU, which includes the Oak Ridge National Laboratory (ORNL) and the Energy Systams' Office of Technology Transfer, is judged to be satisfactory for the period October 1, 1992, to March 31, 1993. Ratings for the major performance areas are as follows:

Performance Ares

Laboratory Management

Sponsor Satisfaction with Research and Development (R\&D)

Program/line Management Operations

Technology Transfer (MMES-Wide)

Research Reactors Operations

Environmental Management (ORNL-Wide)

Safety and Health (S\&H) Management (ORNL-Wide)

Operations

\section{Weight

(9)

10

25

$\boldsymbol{3 0}$

5

5

5

10

10
Bating

Satisfactory

Good

Satisfactory

Outstanding

Good

Good

Satisfactory

Satisfactory

ORNL is one of the Department of Energy's (DOE) major multiprogram laboratories. ORNL conducts applied and basic research in a diverse range of program areas to support the DOE mission. Activitics must be conducted in accordance with DOE direction, federal and state laws, and in a manner that does not cause insult to the environment or endanger the health and safety of employees or the public.

ORNL continues to achieve numerous research accomplishments while conducting operations safely. During the past sir months, achievements include leading the Department in the enhanced technology transfer initiative, significant progress in the Advanced Neutron Source (ANS) project, culminating a multi-year effort in demonstrating the Future Armor Rearm Systems (FARS) technology for the Army, surpassing 100,000 hours of safe operation of the Oak Ridge Electron Linear Accelerator, continuing to promote Departmental initiatives in science and education, and adding two world-class scientific staff to the Distinguished Scientist program. 
Overexpenditures in Work For Others (WFO) programs continue to be a concern. A concern also exists in expenditures in Cooperative Research and Development Agreements (CRADA). Management needs to be more proactive and take the initiative to stop a program or assure receipt of funds prior to overexpenditures occurring. It is noted that ORNL has been proactive on some DOE programs including the Isotopes Facility Shutdown and Conservation programs.

Critical self assessment was one of the several areas noeding empinasis during this award fee period. Self assessment was cited as less than adequate in five out of the last sir award foe periods. In general, both the monthly and the semi-annual self assessments failed to identify deficiencies not already cited by DOE. An improvement is noted, however, in the Environment, Safety, and Health (ES\&H) Compliance and Operations Directorates in self identifying areas for improvement.

Several recent reviews and audits have shown that evidence files for action plan closeouts are not being adequately maintained. Proper and complete data is not being maintained in the evidence files.

Several recent issues indicate the system in place for the communication and implementation of lessons learned across the Laboratory may not be effective. These issues include: "near misses" not being reported, equipment-related fire in Biology, deficiencies noted in the Energy Systems Corporate audit, and unreported occurrences. ORNL has not reached the same level of excellence in safety and health management and operations as ORNL is noted for in research.

The Headquarters (HQ) Sponsor Satiafaction Survey revealed, for the most part, that HQ program aponsors were pleased with ORNL's performance of their programs and projects. However, some HQ program offices were critical and look for ORNL improvement.

Project management has shown progress during this award fee period as evidenced by positive efforts on the High Flux Isotope Reactor (HFIR) Spent Fuel Cask and the ANS projects. However, some major programs such as the High Performance Computing and Communication (HPCC), and oversight of a Conservation Program subcontract with Sullivan Mining Corporation have experienced considerable problems.

The Energy Systems policy defining the roles and responsibilities of program managers is unclear. One effect of this was evidenced early in the period by the overall failure of management responsibility within the Radioisotope Thermoelectric Generator (RTG) program. However, the RTG program has made continued progress during this period. 
In general, the line-management ownership of ES\&E is showing good improvement in the research divisions. However, the lack of conduct of operations, management, and oversight practices for radioactive waste disposal during construction, contributed to the contamination acodent at the Bethel Valley Liquid Low Level Waste Project.

Energy Systems Technology Transfer continues to set the example for the Department in technology transfer. Eleven (11) CRADAs, five in support of intellectual property rights, were executed. Five (5) new license agreements were secured. Energy Systems exceeded the goal for royalty income by receiving $\$ 198,900$ during this period representing sales in excess of $\$ 7 \mathrm{M}$. ORNL performed a significant role in assisting Energy Systems in exceeding their milestones.

The Research Reactors Division (RRD) has accomplished a major feat in significantly reducing the number of personnel contaminations at HFIR (67 percent reduction during the first half of FY 1993 compared to FY 1992). A recent Radiological Protoction Program assessment of HFIR and the Radiochemical Engineering Development Center (REDC) by the HQ-NE indicated that an effective program is in place.

RRD began and continues to aggressively implement a plan of action to reduce the number of reactor scrams. Several of these initiatives have already been put into place.

The environmental management program at ORNL continues to be effective and responsive.

ORNL is to be commended on the handling of and communication on the contamination incident associsted with the Bethel Valley Liquid Low Level Waste Project at Building 2026. Also, the rapid response to the City of Oak Ridge by ORNL to the unidentified spill at the intersection of Bethel Valley and Illinois Avenue is to be complimented. These exhibit ORNL's willingness to cooperate, communicate, and certainly improve its position and posture with regard to its mission in the Department and positive visibility in the community.

ORNL Business Management personnel have kept communications open and up front in dealing with the changing environment affecting the budget process and resulting effects on Laboratory overhead.

The security clearance reduction program, no fire loss, nuclear material and control, and the emergency preparedness programs exhibit a proactive laboratory protection program.

ORNL has shown overall improvement in several areas during this award fee period. However, several areas are rated in the satisfactory range. 
While communications has improved between DOE and ORNL, this area needs continued emphasis.

Section II of this report contains the Executive Summary and Section III contains the detailed commentary which is the basis for this evaluation. It should be noted by the reader that Section III.B. contains verbatim HQ input without OR editorial comment. 


\section{EXECUTTVE SUMAMARY}

\section{A. Laboratory Management}

+ The Metals and Ceramice (M\&C) Division has done an excellent job in bringing Building 3525 into compliance with Environment, Safety, Health, and Quality (ESH\&Q) atandards.

+ Data provided indicates ORNL's performance in the 80cioeconomic program will contribute to Energy Systems meeting or exceeding its annual goal.

+ The support for the DOE metric transition programs was noteworthy.

+ The ORNL Engineering Organization has been very supportive and proactive in supporting DOE Engineering and Construction Projects. Most all milestones have been met, and all reporting requirements have been timely and complete.

- During the first part of this evaluation period, additional quality problems have surfaced in the production of iridium-alloy clad vent sets (CVS) in support of the national RTG program. The identified problems raise the possibility that all vent cup assemblies completed to date may have to be replaced with an estimated cost impact of approximately \$2M.

- ORNL had four overexpenditures in the WFO program. Three required notification of the Secretary of Energy. It is a concern that these problems persist.

B. Sponsor Satisfaction with Research and Development (R\&D)

Refer to Section III.B Sponsor Satiafaction for verbatim narrative provided by HQ program sponsors.

C. Program/line Management Operations

+ A major DOE review substantiated the exceptional quality of the June 30, 1992, ANS Conceptual Design Report (CDR).

+ Detailed plans to facilitate the management of R\&D activities and maintain configuration control were developed as part of the advanced conceptual design for the ANS project.

+ ORNL continues to expand educational opportunities through activities as opening the Regional Science Education Center, a 
June 1, 1993

Executive Committee

W. R. Martin

C. R. Richmond

FY 1993-1 Award Fee Determination Letter

Attached you will find a copy of the award fee determination letter for FY 1993-1. The Laboratory had earlier predicted to Energy Systems management that we anticipated receiving a score of 84 for the period. More specific details regarding how the score was built will not be available until Joe La Grone and Gordon Fee meet at a later date to discuss the fee determination process. As you can see from the chart below, the Laboratory's score dropped the least of all the business units from FY 1992-2.

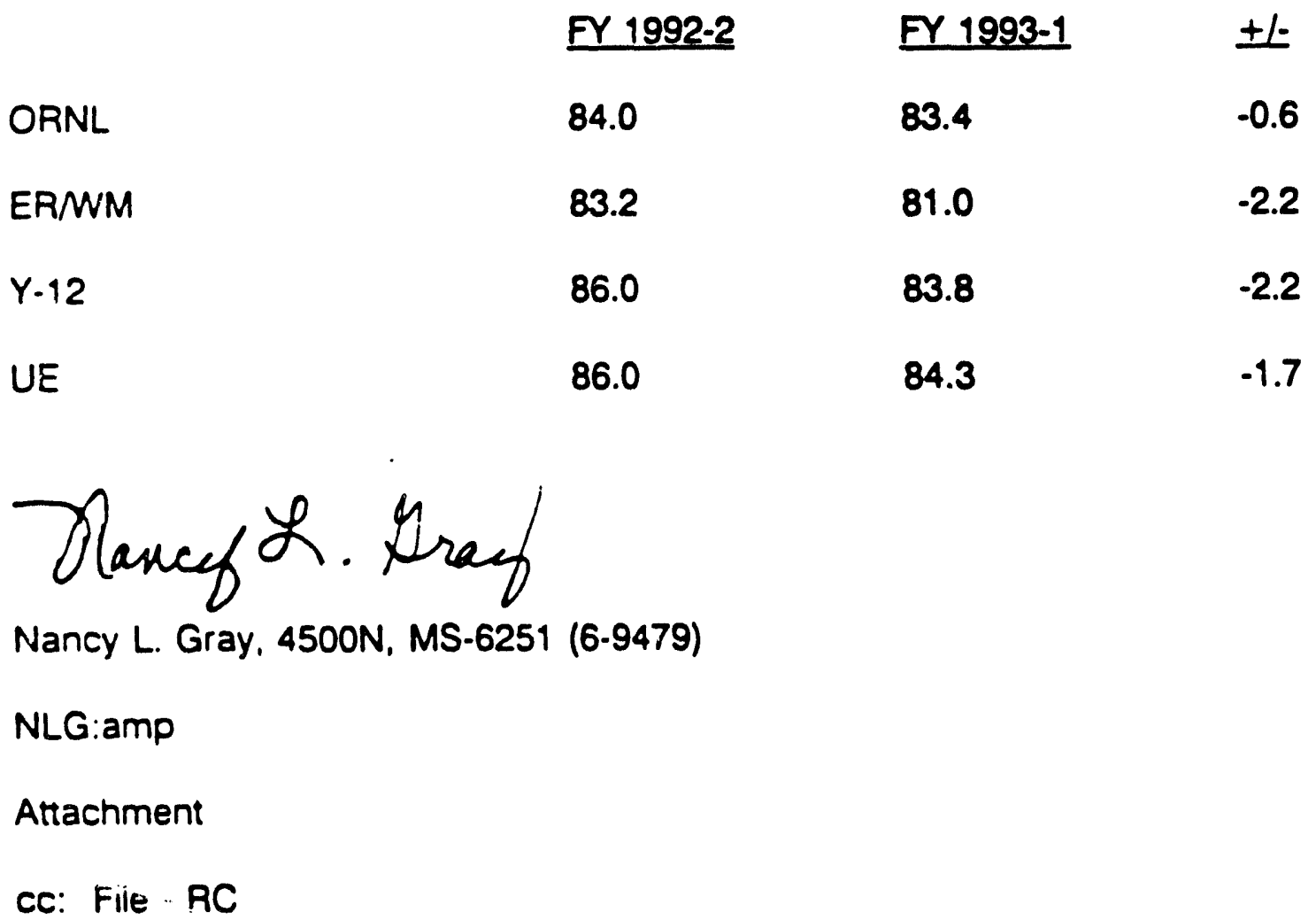




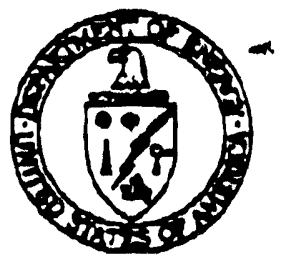

\section{Department of Energy}

Oak Ridoe Fiold Ofrice

P.O. Box 2001

Ook Ridge. Tonnesseo 37801-

May 28, 1993

Air. Gordon 6. Foe, Prasidant

Mertin Marietta Enargy Systems. Ine.

Post Office Box 2009

Dak Ridge, Tennessee 37831-8001

Dear Mr. Fee:

AKARD FEE OETERMIMATION FOR MARTIM MARIETTA ENEREY STSTELS, INC., COKTRACT MO. DE-ACOS-840R21400, FIRST HALF FISCAL VER 2929

I have completed my assessment of Martin Marietta Energy Systems, Inc. (Energy Systems). performance for the evaluation partod October 1. 1992, through March 31. 1993, and have made the following datarnination.

\begin{tabular}{|c|c|c|c|c|}
\hline BUSINESS UNIT & BATRML & A.ABR FEE & & \\
\hline Weapons & Satisfactory & $\$ 1,861,849$ & & 83.8 \\
\hline Laboratory & Satisfactory & 909,653 & $=$ & 83.4 \\
\hline $\begin{array}{l}\text { Environwental Restoration } \\
\text { and Waste Managenent }\end{array}$ & Satisfactory & 451.948 & $=$ & 81 \\
\hline
\end{tabular}

Should you wish to request reconsideration of this detormination, the averaid procedure contatned in Part I of the Performance Evaluation Plan should be followed.

Energy Systems performance was evaluated in the managenent and operation of each of the business units. In arriving at wy deternination, I considered information obtained from the Award Fee Board. Performance Evaluation Comnittees' (Comittees) reports, cognizant Headquarters offlces, as well as Energy Systems self-assessment reports and coments on the Comittees' reports. several Incident/accident investigation raports, other information originating from day-to-day operations, and wy own observations.

The fatal accident which occurred at the Pond Waste Management Project on the ) K-25 Site, the fatal vehlele accldent on Chastnut Ridge Road and the significant shipper/recelvar difference resuiting in the activation of the Department of Energy Anoanily Response Tou were the nost stonificant deficiencies of the parlod and have figured havily into ay fee deteraination.

Sumarized below, by business unit, are the achievenents and deficiencies that formed the basis for ay determination. 


\section{HEAPOHS BUSTHESS UNIT}

Y-12 was very responsive to wany luportant 15sues. The Business Managemont organization did an outstanding job to responding to aultiple "what if" analyses and requests for briefing aterials related to the Fiseal Yoar 1994 Stockptie Support budget. The timeliness and quality of analyses and proposals for reprograming of capltal funds ws a factor in establishing a higher operating budget than was originally allocated. The $Y-12$ Technology Transfer staff worked aggressively with the Department of Energy and the National Institute of Standards and Technology in the signing of a Letter of Agreement estabilshing collaborative affort in the area of manufacturing quality. The $Y-12$ efforts in this 1eportant program are cormendable. Also, the Technology Transfor staff continues to work aggressively in meet ing the goals of transferring technology to the private sector. Their efforts this period include hosting an advanead manufacturing workshop; estabilishing 1-800 number to facilitate access to avallable Oak Ridge technology resources; Initiating several Letters of Agreement, Including a breakthrough agreament. with the Tennessea Valley Authority which extends to Its 7-state ragion; and successfuliy assisting saall businesses under the Regional Assistance Progran. In accordance with the Federal Facilities Compliance Agreanant, Y-12 has certified that all steo-specific corrective actions necessary to comply with the National EnIssion Standard for Hazardous Air Pollutants regulations are complete. The Y-12 Mational Enisston Standard for Hazardous Air Pollutants Program was complimented for its progresstveness, and many aspects of the program were recoamended to be employed at other Oak Ridge Reservation sites. One-hundred percent of the schedules for certification of new containers and recertification of existing containors to support weapons prograns were met. Y-12 performed required testing, subaitted quality Safety Analysis Reports for Packaging documents, and assisted other facilities with improving their packaging prograns. Y-12 continued to be recognized by the Albuquerque Operations Office as the standard of excellence for wapons packaging. The Seawolf Propulsor project continues to meet cost and schedule targets and achieve other major accompitshments. The Havy's confidence in Y-12's abilities has resulted in additional funding for new work. Y-12 closed 745 Occupational Safety and Heal th Administration Risk Assessment Code 2 findings and 2,554 Code 3 findings, which excoeded the established target. A Soll Management Plan which tdentlfies proper managenant of solls during construction and reaediation projects was completed. Use of this document could result in cost savings of several million doliars. Despite the overall reduction in enploysent, wowen and ainority representation rates incroased in many spectfic categories and in overall ropresentation. Praparation and planning for visits by members of the Defense Nuclear Factitiy Safety Board and their staff were noteworthy. The Board comented on the cleani iness and general housekeeping of the butidings they tourad and to responstveness to issues ralsed by the staff. The $Y-12$ Plant has been particularly well organized and responsive to Chearisk's need for extensive access to classified and unclassified historical documents. Energy Systams clearly rocognizes the high priority that is to be given the State's Haith Assessment Studies. 
May 28, 1993

Even though Y-12 lmproved its porformance in IIne-anagenent's feplesentation of safoty and health programs, probleas still extst with had th Physies eveluations of routine work operations and with the contarination control progran. A number of weaknesses have been Identifled in the Nuclear Materials Control and Accountabllity progran at the $Y-12$ Plant. During this perlod, a shipper/receiver difference in a 1989 matortals shipment frou Knolls Atomic Power Laboratory to $Y-12$ was disciosed to the Departaent of Energy for the first time and resulted in the activation of a Departoent of Energy Anomaly Response Team. Issues were Identified regarding coopliance with Materials Control and Accountability order requiresants for parforing inventory and confirmatory mesurements of nuclear antarial in praparation for, and in longterm storage. More attention to the Matorials Control and Accountability progran by $Y-12$ managenent is necessary, espectaliy in viow of consolidation of the Department of Energy's highly anriched uranium at the Y-12 Plant that is under way. The involvement of the Plant Manager to accelerate corrective action is considered vital. Safoty and health requiroments for service order contracts remain a concern. Safoty and halth protectlon for service contractor personnel was identifled as a deftetency in 1990, yet a procedure addressing safoty and health review of service contracts stili has not been issued. Many generator fallures occurred during the period. The related occurrence reports were submitted late and with several inadequate sections. One report was improperly categorized. The quality of occurrence reports in general has become a significant problea.

\section{LABORATORY BUSINESS UNIT}

Oak Ridge National Laboratory (Laboratory) continues to achieve nuwerous research accomplishments while conducting operations safoly. Achtevements include: (1) leading the Dopartment in the enhancad technoingy transfer initiative, (2) achieving significant progress in the Advanced Heutron Source project, (3) cuiminating a mitt-year effort in deanstrating the future Armor Rearm Systems technology for the Arny, (4) surpassing 100,000 hours of safe operation of the Oak Ridge Eectron Linear Accelerator. (5) continuing to promote Departmental initlatives in science and education. and (6) adding two world-class scientific staff members to the Distinguished scientist Program. The Laboratory's performance in the soctoeconomic progran wll significantly contribute to Energy Systems meeting or exceeding its annual goal. The Laboratory exceeded its goal in contracting with saali businass, saall disadvantaged business. and women-owned businass. A major Dapartmant of Energy review substantiated the exceptlonal quality of the Advanced Meutron Source Conceptual Design Report. Detalled plans to facliltate the management of resoarch and development activities and mintain configuration control were developed as part of the advanced conceptual design for the Advanced Neutron Source project. The Laboratory continues to expand educational opportunities through activities such as opening the Reglonal Science Education Center; expanding the Oak Ridge Educational Network assistance in science bowis in three states; and leverage of Department of Energy funds by the Laboratory divisions to provide appointments in the Department of Energy science and Engineering Research Semester. Energy Systems Technology Transfor program continues to set the example and to be the leader in the Department among its 
Managenent and Oporating contractors. Eneray Systems exceeded the goal for royalisy incone durlng this pertod, representing sales in excass of $\$ 7,000,000$. Eleven Cooporative Research and Developoent Agreasants wre executed and 7 now license agraeaents were secured, representing 140 parcent of target. During in on-site reviow by the Headquartars Assistant Secretary for Nuclear Energy, the High Flux Isotope Reactor and Radlochemieal Englneering Dovelopment Center radiological protection control prograss were found to be effective in controlling both radiation axposure of the work force and the public and in controlling contanination. This was considered a ador accomplishaent in that the Assistant Secretary for Nuclear Energy callod Oak Ridge Operations and Energy Systems managesent porsonally pralsing the effoctiveness of the progran. The Research Reactors Division has significantly reduced the number of personnel contaninations at the High Flux Isotope Reactor by 67 parcent during First Kalf Fiscal Year 1993 compared to Fiseal Year 1992 and continues to aggressively implement alan of aetion to reduce the number of reactor scrans. The environiental management program at the Laboratory continues to be effective and responstve. as evidenced by all Radiologleal National Emission Standard for Hezardous Alr Pollutants Fedaral Faclilties Caapliance Agreenent compliance allestones being complated prior to the January 1, 1993, compliance date. The laboratory was prompt and thorough in providing dosiaetry and contanination cantrol sarvices to the eaployees affocted by the Butlding 2026 cesium containation incident. The Laboratory did an outstanding job in roloasing Information to Oak RIdge Operations and to the press in a tinely wanner. Also, the Laboratory's rapid response to the city of Oak Ridge related to the unidentifted spill at the intersection of Bethel Valley Road and Illinois Avenue is to be coupl lmented. The number of Operational Safoty Requiraments violations has decreased ovor the last three perfods. The Laboratory substantially reduced the security patrols' non-negotiated ovartime costs by decreasing the shift-manning raquiraments while maintaining an effective protection leval. The socurlty clearance reduction program resulted in signiftcant long-term cost savings as over 1,700 clearances were identified to be reduced. The Waste Reduction Progran continues to achieve reductions in waste generation as evidenced by the recycling of over 600,000 pounds of paper and corrugated boxes and 7,700 pounds of aluminum cans during this evaluation pertod. The Headquarters Sponsor Satisfaction Survey revealed, for the most part, that Headquarters program sponsors were pleased with the Laboratory's perforance. However, some Headquarters progran offices were critical in many of the same aroas as cited by the Performance Evaluation Conmittees. The Laboratory Business Management personnal have kept comunicattons open with the Laboratory Site office with regard to the changing influences affecting the budget process and resulting effects on the Laboratory's overhead.

While recognizing the wany achievexents at the Laboratory, many deficiencies were also identified. Energy Systeas poltey for definting the roles and responsibilities of progran managors is unclear. One effoct of this was evidenced early in the perlod by the overall fallure of management responsibility within the Radiolsotope Thermolectric Benerator Progran. 
Overexpenditures in the Hork For Othors programs continue to be a concern. A serious lapse of conduct of operations, anaganent, and oversight practicos for radioactive waste disposal during construction of the Bathel Valloy Liquid Low-Level Waste Project contributed to the castum contanination accident in Butldings 2026 and 2099. Management of the High Parforasnce Computing and Coumuntcation Progran and oversight of a consorvation program subcontract with Sulitvan Mining Corporation have experieneed considerabio problems and are not meet ing Department of Eneroy's expectations. Critteal award fee self

assessment was one of sevaral araas requiring emphasis during this award foe period. Self assessant was clted as less than adequate in five of the last six award fae poriods. In general, both the conthly and the sent-annual self assessments falled to Identify defictencies not aiready cited by the Department of Energy. Occurrence roporting/lessons learned are not being consistently conductiod in accordance with requirements of Department of Eneray Order $5000.3 A$, and systems in place for the coumuntcation and 1apleanentation of lessons learned across the laboratory are not effect ive. Severel recent issues include: (1) nany "near misses" are not being reported in the occurrence Reporting and Processing Systea; (2) Iessons learned/root cause of an equipment-related fire in the Biology Division did not prevent another firo occurrence; (3) timely raporting into the Occurrence Reporting and Processing Systea was defictent for a recent Buflding 3025 olectrical near atss and demonstrated lack of understanding of rolas and responsibilitites of involved parties: and (4) unreported occurrencss ware found in log books and el sewhere. A fire protection survalliance revealed daficlencies that have been outstanding since 1991 and a substandard self-assessent progran for vital and major buildings regarding lessons learned from Toxic Substances Control Act Incinerator Fire Investigation. Several recent reviews and audits have show that proper and cosplete data for closure of corrective actlons is not baing maintained in the evidence flles. Also. Energy Systems has falled to keep Performance Indicator data for the Laboratory as requested by the Haadquarters Offtce of Energy Research. There has been an Incrase in the nuaber of Toxic Substances Control ACt Incinerator/Resource Conservation and Recovery Act waste storage non-compliances. An unannounced Occupational Safety and Heaith Admintstration inspection revealed employees had ban exposed to lead at concentrations greater than the Occupational Safoty and Health Administration Denaissible exposure level and had not been notfflad of blood lead results. Electrical deficlencles, incompatible storage of chemicals and conpressed gas cylinders, and firearms safaty deftetencies vere also clted during the period. New parking lot construction was inappropriately charged to expense. When the construetion was approprlately charged, General plant Project funds ware negatively impacted. Improvements are needed in the overall High Flux Isotope Reactor outage management process. Communication and coordination of outage activitles between the various groups working at High Flux Isotope Reactor need to be improved to ensure work activities are consistently well managed.

\section{ENYTRONMENTAL BESTORATTON AND MASTE MANAGEMENT BUSINFSS UNIT}

The K-25 Site reassessment of Individual personnel clearance neods, which resulted in over 1,200 clearances being downgraded, was a noteworthy effort. 
Notable activities at the Toxic Substances Control net incinerator Included performance of the new managurant tean in comploting the fall outage 2 weoks ahead of schodule, below budgot, and wthout incurring any injurtes, environmental upsezs, or occurrancas reportable under Department of Energy Order 5000.3A. It is comendable that a nomination pactage subaltted to the Department of Energy Office of Environiont, Safety, and Health for the K-25 Site Confined Space Entry Program has been selected as oae of the final four to be considarad as an occupational Safety and Haalth worker protection pilot program. The $K-25$ site Environmental Manageane Division Ioplementation of "brown bag luncheons" to cormunicate environantal regulations and plant policies to the grass-roots level of plant personnol is noteworthy. The daily hands-on involvement of the Environental Compl lance Assessments staff cont inues to raise the awareness and understanding of the plant personnel to environmental issues related to routine operations. Outstanding support was provided by Waste Management for recelpt of the David Witherspoon Inc., waste. as woll as decontamination of the Radiation Sterlifizers Inc.. faclifty and recelpt of the Nuclaar Fuel Servicas waste. Efforts to Increase awareness of the Oak Ridge contributions and capabilitties In Technology Development have been comendable. It is noteworthy that the Teehnology logte Diagra offort received high praise froa top-level Hesdquarters managesent and will be the codel for Department of Energy-wide Implomentation. The success of the first Environaental Falr, sponsored by the Environaintal Restoration Progran, is encouraging. The Future Arwor Rearm Systea autonated roloading technolooy and the XY-9] Autoloader desonstration was very successful. The demonstration, wich recelved very positive corments fron the Aray, involved the Future Armor Rearw System vehicle docking with and transferring aumuntion to in MIAl test tank. Contral Staff cont inues to addrass tho Safoty Analysis Raport Upgrades and Facility Safety progran in an aggressive manner by developing integrated inplementation plans for several naw Desartment of Energy ordars, developing triining on the orders for Hoadquarters, and supporting several Safety Analysis Report working groups. Excellent worting relationships are being caintained with the State's Division of Department of Energy Oversight. Central Staff and the three sites have made considerable progress in meeting the State's requests in a timely and coordinated manner.

On November 14, 1992, a Pond Wasto Management Project subcontractor amployea suffered a fatal aceident. Contributing causes Identified by the Department of Energy Type A Investigation Board Includad Energy Systems fallure to provide adequate safety and health oversight and ovaluation feedback to Pond Waste Management Project management and to Chemwaste management, the remediation contractor. As stated before, this fatality was one of the most) significant deficlenctes of the pertod and has figured heavily into ay determination of the fae for this business unit.

This fatality, and the occurrence of other safoty and health incidents during the period, have baen most disappointing. Toxic Substances Control Act Incinerator managemant has been slow in resolving potentlal safaty and health concerns involving equipment inspections and the consistent application of training for waste treatment, storage, and disposal facilities. R-25 site industrial safety oversight and assessment of construction activities has been 
less than adequate to assure the offectiveness of subcontractor safoty prograos. The $k-25$ Safety and Health Division Managers have not been proactive in elosing corrective actlons for 1dentifled progra weaknesses. Multiple wadknesses in the Wasto Management progran had detrinental effects on performance, including cont inued problems wth progras cost planning and performance, poor progress in tapleaenting Genaral plant Projects and lineiten prograns, and ineffectiveness of Central Maste Managenent to function as a IIne organization. A serlous comoltmant to alke the Waste Managenent Program's organizational structure more affectlve is not apparent. Performance of the Environmental Restoration progran at Portsaouth is inadequate. Significant probleas were noted wtth both inattention to the $x$ 749A Closure Project and with a lack of sansitivity to ragulatory requiresents at the $X-701 B$ trench intercept. The inftlal uaste Ares Grouping 6 Proposed plan was inadequate and resulted in considarable controversy and lack of crediblitity with the public. Much additional work is needed at the Energy Systems sites to correct the numerous, proviousiy Identified laboratory and field sampling Quality Assurance/Quality Control 1ssues. Iuprovement in industrial safoty is needed for battor iniementetion of safaty requirements for service contractors and for sor timely development of procedures.

As prevtously stated, the vehicular aceidant fatality on Chestnut Ridge Road is a significant concern and has bean considarad in ov dotormination. Eneroy Systems has responsiblitty to managa, control, and maintain roads on the reservation, including Chestnut Ridge Rosd where the accident oceurred.

We expect you and/or your staff nambers to waet with our sentor managers and their staff members to discuss the basis for the ratings Energy Systeras received. Hopefully, these discussions will elartfy any areas of misunderstanding.

I have instructed Contracting Officer's Representatives to begin working with their respectlve Energy Systems counterparts to correct Identifind deficiencies, and I look forward to discussing progress during our weakly meetings.

Sincerely,

FM-733:Taylor

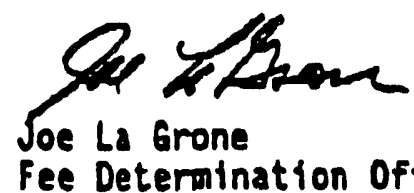

Fee Determination Offictal 
Appendix $\mathbf{B}$

MATRX MANAGEMENT UPGRADE SOLUTIONS TEAM CHARTER 


\section{Appendix B}

\section{MATRIX MANAGEMENT UPGRADE SOLUTIONS TEAM CHARTER CHARTER OF RESPONSIBIUTY, ACCOUNTABILTY, AND AUTHORITY}

The Matrix Management Upgrade Solutions Team (MMUST) is established and chartered as an independent Team that is responsible to the Oak Ridge National Laboratory (ORNL) Division/Program/Office Directors Caucus (the Caucus). The Team is chaired by a Robotics \& Process Systems Division Section Head and consists of management representatives from divisions and programs throughout ORNL.

The Team will identify and recommend improvements in program and project management at ORNL which lead to resolution of concerns about ORNL performance in this area. Among the concerns expressed are the Department of Energy-Oak Ridge Operations concerns about missed milestones, budget overruns, and late deliverables. Also, Program, Project, and Line Managers at ORNL, Y-12, and K-25 have voiced concerns about lack of authority, interface difficulties, unresponsive organizations, and inadequate management support. In addition to addressing these concerns, the improvements recommended should include useful information and methods which help ORNL staff members to better plan and carry out technical work within budget and schedule constraints. The scope and detail of the recommendations. will be determined by the Team.

The Team will also provide guidance and support for implementation of recommendations accepted by ORNL and will determine methods to assess the effectiveness of these improvements. The scope of this aspect of the Team responsibilities will be determined by the Team based on the recommendations to be implemented.

While the Team will principally address program and project management issues for ORNL, some of the issues cross-cut and involve organizations at Y-12 and K-25. The improvements recommended by the team may address some MMES-wide issues.

As part of this work the Team will solicit and consider suggestions and proposals from all directorates, divisions, and program offices. In some cases individuals making suggestions or proposals will be asked to work directly with the Team.

The Caucus will serve as a steering committee for the Team. The Team will provide periodic briefings to the Caucus and will be guided by the response to those briefings.

After six months (December 1993) the Team will evaluate its progress relative to this charter and will determine if continuation of Team activities is appropriate and necessary. The results of this evaluation will be provided to the Caucus.

The Team Chair is responsible for establishing the means for the Team to accomplish these missions. He will request and utilize the resources of participating divisions, programs, and directorates as needed for support. 
Appendix C

SUCCESSFUL PROGRAM/PROJECT SUMMARY DESCRIPTIONS 
Appendix C

\section{SUCCESSFUL PROGRAM/PROJECT SUMMARY DESCRIPTIONS}

This appendix contains summary descriptions of programs and projects at Oak Ridge National Laboratory (ORNL) that were completed successfully during the past two years. This is not a comprehensive listing of all successfully completed programs and projects but rather is a sampling of those items based on a limited survey of ORNL division and program offices. More thorough information on each program and project summarized in this appendix is on file in the record files for the Matrix Management Upgrade Solutions Team (MMUST) activities.

ITEM 1

Program/Project Title: West Valley Transfer Cart Control System

\section{Summary Program/Project Description:}

Oak Ridge National Laboratory (ORNL) completed conceptual and detail design of the control system for the West Valley Vitrification Facility transfer cart. The primary objective of the West Valley Vitrification Facility is to solidify the high-level radioactive waste stored in underground tanks at the former Nuclear Fuel Services reprocessing plant into a form suitable for transportation and disposal. The transfer cart will transfer canisters of vitrified high-level waste remotely within the Vitrification Facility. The design of the transfer cart was a joint effort by West Valley Nuclear Services and ORNL. Generally, ORNL had the responsibility for the design of the West Valley Transfer Cart Control System. The control system will operate the cart under battery power by wireless control. The equipment includes cart-mounted electrical equipment, cart control pendants, an engineer's control console, a battery charger, and the communication antennas in the facility. At present, the equipment is being fabricated by a subcontractor. ORNL is still participating in the effort providing fabrication and testing support as well as control system software.

Responsible Lead ORNL Organization:

ORNL Robotics \& Process Systems Division

Sponsoring Organization:

West Valley Nuclear Services and DOE-ER

Sponsor/Customer Satisfaction Level:

The sponsor/customer was very satisfied. 
ITEM 2

Program/Project Tite: Fuel Disassembly System Detail Design

Summary Program/Project Description:

Oak Ridge National Laboratory (ORNL) completed the detail design of the Fuel Disassembly System (FDS) for the Recycle Equipment Test Facility (RETF) in Japan. The FDS equipment will perform the functions of disassembling spent fuel from two Japanese breeder reactors, MONJU and JOYO, for reprocessing. The design consists of mechanical equipment for handling the fuel assemblies and performing laser cutting. Design of electrical, instrumentation, and control equipment was also provided. ORNL also provided design analysis documentation including a safety analysis, radiation-shielding analysis, seismic analysis, mechanical design calculations, and laser optics design analysis. The detail design of the remotely operated fuel disassembly equipment was based on the Consolidated Fuel Reprocessing Program's development work in laser fuel disassembly. The FDS design has been delivered to the Power Reactor and Nuclear Fuel Development Corporation (PNC) to be fabricated and tested in Japan prior to being installed in the RETF.

Responsible Lead ORNL Organization:

ORNL Robotics \& Process Systems Division

Sponsoring Organization:

PNC of Japan

Sponsor/Customer Satisfaction Level:

The sponsor/customer was satisfied.

ITEM 3

Program/Project Title: $\quad$ Ammunition Logistics Program Future Armor Rearm System (FARS)

\section{Summary Program/Project Description:}

The FARS Project developed and demonstrated automated ammunition resupply technology in support of the U.S. Army's Project Manager for Ammunition Logistics (PM-AMMOLOG). FARS consists of a tracked, armored chassis and a specialized mission module for automatically handling M1A1 tank ammunition. The resupply system developed utilizes advanced automated controls, robotics, and telerobotics technology. It allows the soldiers to remain safely under sealed and armor 
protection while remotely loading ammunition from FARS into the tank storage system. The technology was successfully demonstrated in January 1993.

Responsible Lead ORNL Organization:

The Ammunition Logistics Program in the Robotics \& Process Systems Division of the Oak Ridge National Laboratory was responsible for the FARS Project.

\section{Sponsoring Organization:}

U.S. Army PM-AMMOLOG, Picatinny Arsenal

U.S. Army Project Manager for Tank Main Armament Systems, Picatinny Arsenal

\section{Sponsor/Customer Satisfaction Level:}

The sponsor/customer has bestowed numerous accolades on the FARS team, and several Certificates of Achievement and awards have been presented. The latest is a Certificate of Achievement that states, "Awarded to the FARS Team with sincere gratitude for their dedicated professional efforts which have resulted in the extremely successful completion of the FARS program on time and within budget." The certificate is signed by Col. Thomas Tobin, project manager of Ammunition Logistics, and is dated October 6, 1993.

\section{ITEM 4}

Program/Project Tite: Design Considerations for a 1-kWh Energy Storage Magnet

\section{Summary Program/Project Description:}

The objective of this project was to examine issues related to design of a test magnet wound with multifilamuntary, silver/bismuth-strontium-calcium-copper oxide, high-temperature superconducting wire. Superconductivity, Inc., proposed a 5-kJ magnet operating in the temperature range of 20 to $40 \mathrm{~K}$ with an average power rating of $4 \mathrm{~kW}$. Owing to the low current density, substantial difference between critical and operating temperatures, and large specific heats at high temperatures, the growth of normal zones is slow, complicating the detection of incipient normal zones. This study indicated that the normal-zone voltage becomes large enough to detect reliably before the hot-spot temperature reaches harmful levels.

Responsible Lead ORNL Organization:

Superconductivity Partnerships Program, Central Management Offices 
Sponsoring Organizations:

DOE-EE

Superconductivity, Inc.

Sponsor/Customer Satisfaction Level:

While the sponsor/customer was satisfied, no formal documentation of customer satisfaction was obtained.

ITEM 5

Program/Project Titte: Multiple Laser Beam and Segmented Target Laser Ablation Application to High $\mathrm{T}_{\mathrm{c}}$ Superconducting (HTSC) Film Deposition

Summary Program/Project Description:

The objective of this pilot center cooperative agreement between ORNL and Neocera, Inc., was to develop a computer-controlled, multitarget laser ablation deposition system [the Automated Multilayer Deposition Accessory (AMDA)] for growing high-quality thin and thick superconducting films.

Responsible Lead ORNL Organization:

Superconductivity Partnerships Program, Central Management Offices

Sponsoring Organizations:

DOE-EE

Neocera, Inc.

Sponsor/Customer Satisfaction Level:

The sponsor/customer was satisfied. Neocera has a product-the AMDA-on the market. They have also applied for a copyright on the system control software developed under the agreement. The AMDA was presented at the Fall 1992 Materials Research Society Meeting, and follow-up to leads developed from that show continue. (No formal documentation of customer satisfaction was obtained.) 
ITEM 6

Program/Project Tite: In Situ Monitoring of the Preparation of HTSC Films

Summary Program/Project Description:

The primary objective of this project was to develop an in situ monitoring method for preparation of high- $T_{c}$ superconducting films. ORNL's effort centered on the gas phase kinetics of the laser ablation deposition process. The Advanced Fuel Research Group, primarily supported by the Strategic Defense Initiative Office, developed a new method for achieving simultaneous emission/reflection Fourier Transform Infrared (FTIR) spectroscopy. A unique method to invert a measured FTIR reflectance spectrum to yield the optical constants of the film was developed. Two prototype instruments were constructed and tested for possible commercialization. The ability to reveal compositional changes in high- . $_{c}$ superconducting films during annealing was demonstrated.

Responsible Lead ORNL Organization:

Superconductivity Partnerships Program, Central Management Offices

Sponsoring Organizations:

DOE-EE

Advanced Fuel Research, Inc.

Sponsor/Customer Satisfaction Level:

While the sponsor/customer was satisfied, no formal documentation of customer satisfaction was obtained.

ITEM 7

Program/Project Titte: YBCO and BSCCO Thick Film Superconductors on Practical Substrates

\section{Summary Program/Project Description:}

$\mathrm{Bi}_{2} \mathrm{Sr}_{2} \mathrm{CaCu}_{2} \mathrm{O}_{8}$ thick films were grown on silver substrates by the partial melt growth technique to form high-temperature superconducting tapes. Critical temperatures of 82 to $85 \mathrm{~K}$ and critical current densities of 0.5 to $4 \times 10^{5} \mathrm{~A} \mathrm{~cm}^{2}$ in the 4.2- to 20-K temperature range were routinely obtained. The quality of the tape and the superconducting transport properties were found to depend on two parameters: the time spent at maximum processing temperature and the maximum processing temperature itself. The optimum setting of these parameters was also found to be dependent on the powder precursor quality and the film thickness. 
Responsible Lead ORNL Organization:

Superconductivity Partnerships Program, Central Management Offices

Sponsoring Organizations:

DOE-EE

State University of New York at Buffalo (SUNY)

Sponsor/Customer Satisfaction Lovel:

While the sponsor/customer was satisfied, no formal documentation of customer satisfaction was obtained.

ITEM 8

Program/Project Title: Enhancement of Toxicological Profiles [Agency for Toxic Substances and Disease Registry (ATSDR) ATSDR Toxicity Profiles]

Summary Program/Project Description:

This project involved preparation of toxicological profiles of chemicals mandated by the Superfund Amendments and Reauthorization Act of 1986. Toxicological profiles will provide comprehensive toxicological and health effort information to federal and state public health professionals involved in hazardous waste cleanup missions.

Responsible Lead ORNL Organization:

Biomedical and Environmental Information Analysis

Sponsoring Organization:

ATSDR

Sponsor/Customer Satisfaction Level:

The sponsor/customer satisfaction level was good. 
ITEM 9

Program/Projoct Title: Radiological Performance Assessment of the Savannah River Site Saltstone Disposal Facility

Summary Program/Project Description:

A radiological performance assessment (RPA), as required by Department of Energy (DOE) Order 5820.2A, was completed for the Savannah River Site Saltstone Disposal Facility (SDF) in May of 1993. The RPA requires an all-pathways predictive analysis of potential exposure of the general public and inadvertent intruders to radionuclides in, or leached from, radioactive waste facilities. Site specific data were used to develop (1) a source term model, including consideration of degradation of engineered features; (2) exposure scenarios for inadvertent intruders; and (3) a groundwater model for the potentially impacted region. The methodologies and results were submitted to DOE's Performance Assessment Peer Review Panel, as is required by the DOE order. After the panel's questions and comments were addressed, the panel approved the SDF RPA as a technically defensible analysis of the potential impacts of the low-level waste facility. The SDF RPA is the first RPA in the DOE system to be approved by this panel.

Responsible Lead ORNL Organization:

Environmental Technology Section, Health Sciences Research Division

Sponsoring Organizations:

DOE-EM

Sponsor/Customer Satisfaction Lovel:

Because the Saltstone Disposal Facility Radiological Performance Assessment was completed within budget, on time, and was approved by the DOE Performance Assessment Peer Review Panel, the sponsor Westinghouse Savannah River Company) satisfaction level was very high.

ITEM 10

Program/Project Title: ER\&WM Robotics Technology Development Program 3RAT Robotics Technology Development Roll-Up (OR138201)

Summary Program/Project Description:

The Department of Energy Office of Technology Development's (OTD's) Robotics Technology Development Program (RTDP) was structured into eight major 
elements covering application areas and a cross-cutting and technology development activity. Work in each of the program elements was performed by a multisite team; element activities were coordinated by a designated lead site. Each of the elements has established major technology thrust areas within which the development activities of the team participants were defined. Oak Ridge National Laboratory (ORNL) was a participating site member in all RTDP activities. The major elements structured under the FY 1993 RTDP are:

- Underground Storage Tanks-East (UST-E),

- Underground Storage Tanks-West (UST-W),

- Buried Waste (BW),

- Decontamination and Decommissioning (D\&D),

- Waste Facility Operations (WFO),

- Waste Processing Operations (WPO),

- Contaminant Analysis Automation (CAA), and

- Cross-Cutting and Advanced technology (CC\&AT).

Responsible Lead ORNL Organization:

Robotics \& Process Systems Division

Sponsoring Organizations:

DOE-ER\&WM OTD

Sponsor/Customer Satisfaction Level:

The customer was satisfied. Follow-on funding was confirmed for FY 1994.

ITEM 11

Program/Project Titte: ER\&WM Underground Storage Tanks Integrated Demonstration (USTID) 3RAP LRA-Control System (OR132001)

\section{Summary Program Description:}

The objective of this project was to develop and to demonstrate robotics technology for characterization and remediation of underground storage tanks. The emphasis was to support a multilaboratory effort to develop and to demonstrate waste tank retrieval technologies based on use of the long-reach manipulator (LRM) as the primary end-effector positioning system. The tasks and funding were complementary to USTID tasks at six other Department of Energy sites and a related set of tasks submitted for the Office of Technology Development (OTD), Robotics Technology Development Program under the UST-W application area. 


\section{Summary Project Description:}

The completed tasks are as follows:

- $\quad$ ORNL collaborated with Pacific Northwest Laboratories (PNL) in kinematic and dynamic performance analyses of the prototype LRM and candidate retrieval system. A rigid-body dynamic model was developed for LRM configurations. This model was combined with a model generated by PNL for a short-reach manipulator and waste-dislodging end-effectors. The combined model is used for manipulator dynamic studies.

- ORNL performed a human-factors-based, retrieval system, control console design based on a task analysis and system analysis focused on definition of operator responsibilities.

Responsible Lead ORNL Organization:

Robotics \& Process Systems Division

Sponsoring Organizations:

DOE-ER\&WM OTD

Sponsor/Customer Satisfaction Level:

The sponsor/customer was satisfied. Follow-on funding was confirmed for FY 1994.

ITEM 12

Program/Project Title: ER\&WM Underground Storage Tanks Integrated Demonstration (USTID) 3RAV Early Deployment System (EDS) (OR132018)

\section{Summary Program Description:}

The objective of this task was to develop and to demonstrate robotics technology for characterization of underground storage tanks. The emphasis was to support a multilaboratory effort to develop and to demonstrate waste tank characterization technologies for use with the EDS and the Light Duty Utility Arm (LDUA). The task and funding were complementary to USTID tasks at six other DOE sites and a related set of tasks submitted for the Office of Technology Development Robotics Technology Development Program under the UST-W application area. 
Summary Project Description:

- ORNL collaborated with Sandia National Laboratories and Mechanical Technology Incorporated to develop and to demonstrate a structured light source for mapping waste and tank surfaces inside the underground storage tanks at the Hanford site. This sensor system is a subsystem of the EDS, which was coordinated through Pacific Northwest Laboratories and is also being utilized by the LDUA, which was coordinated by Westinghouse Hanford Corporation.

Responsible Lead ORNL Organization:

Robotics \& Process Systems Division

Sponsoring Organizations:

DOE-ER\&WM OTD

Sponsor/Customer Satisfaction Level:

The sponsor/customer was satisfied.

ITEM 13

Program/Project Titte: ER\&WM Buried Waste Integrated Demonstration (BWID) 3RAS Remote Excavation/Characterization System Demonstration Roll-up (OR132013)

\section{Summary Program Description:}

This program addresses demonstration of technologies being developed under the Robotics Technology Development Program (RTDP) in support of the BWID Program. One of the technology areas within the RTDP is the Buried Waste Robotics Program (BWRP), which is chartered to develop technologies to assist in the remediation of buried waste sites. These remediation tasks include waste characterization, retrieval, and treatment using remote-controlled devices that will remove an operator from the hazardous environment and increase the speed of operations, which will increase safety and reduce the overall cost.

\section{Summary Project Description:}

The work scope for this project was to demonstrate subsurface mapping using a remotely operated device for the waste characterization function and to demonstrate a remotely operated device for the waste retrieval function under the BWRP for BWID. A Remote Characterization System (RCS) was developed consisting of an advanced remotely operated, low-signature (low-metallic) platform, 
a high-level control station, a Global Positioning System, and a suite of advanced geophysical sensors. Also developed was a Remote Excavation System (RES) jointly with the Department of Defense, U.S. Army. The U.S. Army contracted ORNL for the development of teleoperation of the backhoe and front loader (endeffectors) of an existing excavation vehicle called the Small Emplacement Excavator. The RES is being used to provide remote excavation of waste forms on the Idaho National Engineering Laboratory Cold Test Pit.

\section{Responsible Lead ORNL Organization:}

Robotics \& Process Systems Division

\section{Sponsoring Organizations:}

DOE-ER\&WM/OTD

\section{Sponsor/Customer Satisfaction Level:}

The sponsor/customer was satisfied. Major demonstrations of the RCS and RES were completed. Follow-on funding confirmed for FY 1994.

ITEM 14

Program/Project Titte: All-Terrain Lifter, .Articulated System (ATLAS)

\section{Summary Program/Project Description:}

The ATLAS Project successfully developed, implemented, and demonstrated a novel methodology for resolving the redundancy of robotic manipulators. This new methodology was implemented on the ATLAS vehicle to provide a proof-ofprinciple demonstration of the novel analytical approach, and as a technology transfer to the U.S. Army. ATLAS is a field material-handling vehicle prototype that incorporates a mobile platform with a manipulator supporting a forklift end-effector. ATLAS is used by the U.S. Army to investigate automation and speed-up of battlefield logistic support functions such as cargo and ammunition transfer previously done mostly by hand (e.g., in the Persian Gulf). The implemented system automatically coordinates all moving joints of the ATLAS boom (which is kinematically redundant) to allow personnel to directly control the end-effector motion when picking up and manipulating cargos (in a way similar to a "fly-by-wire" system). Additionally, a sensor-based "anti-tip-over" function was added to ATLAS to warn the operator of approaching static and dynamic stability limits when transferring heavy cargos of unknown weights. 
Responsible Lead ORNL Organization:

Francois G. Pin, 574-6130

Autonomous Robotic Systems Group

Intelligent Systems Section

Center for Engineering Systems Advanced Research

Engineering Physics and Mathematics Division

Sponsoring Organization:

U.S. Army Belvoir Research Development and Engineering Center

Sponsor/Customer Satisfaction Level:

The high sponsor/customer satisfaction level resulted in a Special Achievement Award and an Energy Systems President's Award to the project team.

ITEM 15

Program/Project Title: Japanese-American Shielding Program of Experimental Research (JASPER)

Summary Program/Project Description:

JASPER was a joint DOE and Japan Power Reactor and Nuclear Fuel Development Corporation experimental shielding research to support the development of advanced sodium-cooled power reactors by extending the existing base of shielding-related integral experiment data.

Responsible Lead ORNL Organization:

Engineering Physics and Mathematics Division

Sponsoring Organizations:

DOE-NE

Sponsor/Customer Satisfaction Level:

Sponsor/customer satisfaction level was medium to high.

ITEM 16

Program/Project Titte: Review Criteria for Human Factors Aspects of Advanced Controls and Instrumentation (NRC FIN \# B0852) 


\section{Summary Program/Project Description:}

The objective of the project was to contribute to the development and refinement of regulatory review guidelines for use in evaluating advanced instrumentation and control systems in nuclear power plants. During the research, the existing NUREG0700 guidelines were integrated into the advanced control room design review (ACRDR) guidelines being developed. The need for new guidelines to enhance the ACRDR guidelines were subsequently assessed. Then, the ACRDR guidelines were converted into a form and format compatible with nuclear industry needs. Finally, new ACRDR guidelines was developed for selected advanced control/display technologies.

Responsible Lead ORNL Organization:

Cognitive Systems and Human Factors Group Intelligent Systems Section

Engineering Physics and Mathematics Division

Sponsoring Organizations:

Nuclear Regulatory Commission

Office of Nuclear Regulatory Research

Division of Systems Research

Sponsor/Customer Satisfaction Level:

The sponsor/customer was satisfied.

ITEM 17

Program/Project Title: Department of Energy/Power Reactor and Nuclear Fuel Development Corporation Joint Collaboration

\section{Summary Program/Project Description:}

The Department of Energy (DOE) and the Power Reactor and Nuclear Fuel Development Corporation (PNC) entered into an agreement for a five-year joint research and development (R\&D) collaboration in breeder reprocessing technology, which began in FY 1987. At the end of this initial five-year period (FY 992), an agreement was reached to extend the test program through FY 1993. This collaborative R\&D effort focused on support of the PNC Recycle Equipment Test Facility (RETF). During the initial five years of the agreement, the work was in the following major areas: continuous head-end process technology, chemical process technology, advanced remote technology, and design optimization of the RETF. The FY 1992 and FY 1993 work centered around test programs aimed at 
confirming design information and gathering licensing data for the RETF dissolution and solvent extraction systems. The RETF prototypic dissolution and solvent extraction test equipment installed at the Robotics \& Process Systems Complex were used to conduct this test program.

\section{Responsible Lead ORNL Organization:}

\section{Robotics \& Process Systems Division}

\section{Sponsoring Organization:}

Power Reactor and Nuclear Fuel Development Corporation DOE-NE

\section{Sponsor/Customer Satisfaction Level:}

PNC has a strong desire to see that this collaboration continue for a number of years. Both PNC and DOE regard this collaboration as a quality prigram that has produced a number of solid technical results. PNC regards the technical results of the dissolver and solvent extraction test programs as being essential to the successful licensing of the RETF. They have been very complimentary of the support provided to them by the Oak Ridge National Laboratory.

ITEM 18

Program/Project Titte: Atomic Vapor Laser Isotope Separation (AVLIS) Product Purification

\section{Summary Program/Project Description:}

This demonstration and experimental project was conducted to confirm that aqueous-based processes could be used to purify the AVLIS metal product to American Society for Testing and Materials specifications for fuel grade uranium oxides. This project first obtained laboratory data on the dissolution rate of the AVLIS product. Based on this data, the project then began the effort to purify sufficient material to allow the preparation of 30 to $50 \mathrm{~kg}$ of uranium oxide for later in-reactor testing. This purification required the dissolution of the metal product followed by solvent extraction purification. The process steps selected were an outgrowth of our experience in nuclear fuel reprocessing and were strongly influenced by the PUREX process. Purification required meeting or exceeding product quality specifications for $20+$ contaminant elements. Verification of product purity required the selection/mixing of several analytic chemistry techniques to overcome the difficulties of analyzing uranyl nitrate solutions for partper-million levels of impurities. Because the composition of the AVLIS product was classified, this project also required special security requirements. 
Responsible I ead ORNL Organization:

Robotics \& Process Systems Division, Process Technology Section

Sponsoring Organization:

AVLIS Division

Sponsor/Customer Satisfaction Level:

The customer was pleased with the quality of the technical results and of our successful meeting of the product quality specifications. Some communication problems resulted in a misunderstanding of one of the deliverables. Once this was addressed at the project/division level, all other commitments were met in a timely fashion. A follow-on project to concentrate the purified product was conducted in FY 1993 by the same project team.

ITEM 19

Program/Project Title: Y-12 Plant Solvent Extraction Flowsheet Development

\section{Summary Program/Project Description:}

This continuing experimental program is being performed to evaluate potential improvements to processes currently used by the Y-12 Plant to recover enriched uranium "scrap" from machining, casting, and maintenance operations. Recovered material is currently purified in a two-step solvent extraction process. In the first (primary) process, some purification is achieved by extraction using dibutyl carbinol as the solvent. In the second purification step (secondary extraction), final purification is accomplished in an extraction process using tributyl phosphate in AMSCO diluent as the solvent. Both processes are currently performed using pulsed solvent extraction columns. The subject task is currently directed toward developing a flowsheet for the primary extraction process in which centrifugal contactors are used in place of pulsed columns. Centrifugal devices have been demonstrated to respond to process upsets more rapidly than pulsed columns. In addition, centrifuges operate with smaller inventories of in-process solution than pulsed columns, require considerably less space, and are easy to drain in order to perform required strategic material inventories. Use of additives to the currently used primary process solvent is under way, and evaluations of atternative solvents are also being performed.

Responsible Lead ORNL Organization:

Robotics \& Process Systems Division, Process Technology Section 
Sponsoring Organization:

Y-12 Plant Development Division

Sponsor/Customer Satisfaction Level:

The customer has demonstrated such satisfaction with this work that funding has been renewed annually for four consecutive fiscal years. During this period the level of funding has remained constant. Commitments to the customer have been met as scheduled. The objectives of the work have occasionally required revision in response to experimental findings.

ITEM 20

Program/Project Title: Measurements on High-Temperature Superconductors

Summary Program/Project Description:

This project involved testing new high-temperature superconductors and coils for

U.S. industry.

Responsible Lead ORNL Organization:

Fusion Energy Division/ORNL Superconductor Pilot Center

Sponsoring Organization:

U.S. Industry

Sponsor/Customer Satisfaction Level:

All milestones were met on cost.

ITEM 21

Program/Project Title: Faraday Shield Upgrade for the DIII-D Tokamak

Summary Program/Project Description:

This project consisted of designing, building, and installing a new Faraday shield for the DIII-D RF heating antennas.

Responsible Lead ORNL Organization:

Fusion Energy Division 
Sponsoring Organization:

DOE-Office of Fusion Energy and General Atomics

Sponsor/Customer Satisfaction Level:

The schedule was met, the cost was only $15 \%$ over initial estimate, and the shield worked exceptionally well.

ITEM 22

Program/Project Titte: Reflectometer Diagnostic for Tokamak Fusion Test Reactor (TFTR)

Summary Program/Project Description:

This project consisted of design, construction, and operation of an advanced diagnostic for use on TFTR at the Princeton Plasma Physics Laboratory (PPPL).

Responsible Lead ORNL Organization:

Fusion Energy Division

Sponsoring Organization:

DOE-OFE and PPPL

Sponsor/Customer Satisfaction Level:

The project was below estimated cost and ahead of schedule.

ITEM 23

Program/Project Titte: Phase Control System for DIII-D for Current Drive Antennas

Summary Program/Project Description:

This project consisted of developing a prototype for a Phase Control System for DIII-D at the Oak Ridge National Laboratory together with installation and operation at General Atomics.

Responsible Lead ORNL Organization:

Fusion Energy Division 
Sponsoring Organization:

DOE-OFE and General Atomics

Sponsor/Customer Satisfaction Level:

Both estimated cost and schedule were met. The system worked very well.

ITEM 24

Program/Project Title: Folded Waveguide Development Program

Summary Program/Project Description:

This project consisted of designing, building, and performing preliminary testing of the first folded waveguide radio frequency antenna.

Responsible Lead ORNL Organization:

Fusion Energy Division

Sponsoring Organization:

DOE-OFE

Sponsor/Customer Satisfaction Level:

Both estimated cost and milestones were met. The folded waveguide radio frequency antenna worked better than expected.

ITEM 25

Program/Project Titte: Mobile Microwave Concrete Removal System

Summary Program/Project Description:

This project consisted of design, construction, and testing of a new, efficient system for removing concrete with microwaves.

Responsible Lead ORNL Organization:

Fusion Energy Division

Sponsoring Organization:

DOE-Office of Technology Development/ES-Washington R\&D 
Sponsor/Customer Satisfaction Level:

The project was completed on schedule and at the projected cost. The system worked very well.

ITEM 26

Program/Project Title: Vacuum Pumping and Shielding on Tokamak Physics Experiment (TPX)

Summary Program/Project Description:

This project consisted of design and engineering of the vacuum, pumping, and shielding systems on the TPX at the Princeton Plasma Physics Laboratory (PPPL).

Responsible Lead ORNL Organization:

Fusion Energy Division and ES-Engineering

Sponsoring Organization:

DOE-OFE and PPPL

Sponsor/Customer Satisfaction Level:

The project was completed on schedule and estimated costs were met.

\section{ITEM 27}

Program/Project Tite: Army Sintering Program

Summary Program/Project Description:

This project included the use of microwave sintering to toughen armor for tanks.

Responsible Lead ORNL Organization:

Engineering Technology Division

Sponsoring Organization:

U.S. Army

Sponsor/Customer Satisfaction Level:

The project was completed on schedule and estimated costs were met. 
ITEM 28

Program/Project Titte: Tritium Pellet Injector for The Tokamak Fusion Test Reactor (TFTR)

Summary Program/Project Description:

This project consisted of providing a tritium pellet injector with speeds of $1.3 \mathrm{~km} / \mathrm{s}$ and pellet size 3.3 to $4.5 \mathrm{~mm}$ diam for fueling the TFTR plasma at the Princeton Plasma Physics Laboratory (PPPL).

Responsible Lead ORNL Organization:

Fusion Energy Division

Sponsoring Organization:

DOE-OFE and PPPL

Sponsor/Customer Satisfaction Level:

Sponsor/customer satisfaction was high; costs were under the estimated budget.

ITEM 29

Program/Project Title: Support of United Kingdom (U.K.) Spherical Torus Program

Summary Program/Project Description:

This project supported design and operation of a spherical torus, (i.e., low-aspectratio tokamak, developed by the Oak Ridge National Laboratory (ORNL) at the Culham Laboratory, United Kingdom.

Responsible Lead ORNL Organization:

Fusion Energy Division

Sponsoring Organization:

DOE-OFE/United Kingdom Atomic Energy Authority, Culham

Sponsor/Customer Satisfaction Level:

Sponsor/customer satisfaction was high. 
ITEM 30

Program/Project Title: New Production Reactors Program

Summary Program/Project Description:

Beginning in FY 1990 and ending in FY 1993 the Department of Energy supported significant efforts toward the development of reactor concepts for weapons materials production. The major emphasis was on a Heavy Water Reactor (HWR) and a Modular High Temperature Gas-Cooled Reactor (MHTGR). The Oak Ridge National Laboratory (ORNL) was the lead Laboratory for structural materials and various engineering aspects of the HWR. Lead Laboratory status was also held by ORNL for structural materials for the MHTGR. Additionally, the majority of the MHTGR fuels experimental work was done at ORNL with funding provided through EG\&G Idaho.

Responsible Lead ORNL Organization:

Reactor Programs Office

Sponsoring Organization:

DOE-NP (Office of New Production Reactors)

Sponsor/Customer Satisfaction Level:

Sponsor/customer satisfaction was high.

ITEM 31

Program/Project Title: National Emission Standards for Hazardous Air Pollutants Stack Upgrade Program

\section{Summary Program/Project Description:}

In December 1989, new federal regulations were promulgated that changed the criteria used to evaluate radiological air effluents from Department of Energy (DOE) facilities. The changes in the regulations required major modifications to the existing compliance sampling systems at the Oak Ridge National Laboratory's (ORNL) major air effluent sources. The sources that were modified under this program include four major sources, stacks 2026, 3020,3039, and 7911, and two minor sources, stack 2000 and 7512 . New instrumentation was procured and installed to meet the new criteria. In some instances, changes in the physical location in the stacks were also made. A Federal Facilities Compliance Agreement was signed between DOE and the Environmental Protection Agency that included a compliance schedule with required milestones-the stack improvements were a major portion of the milestones. 
Responsible Lead ORNL Organization:

Office of Environmental Compliance and Documentation

Sponsoring Organization:

DOE-ER10

Sponsor/Customer Satisfaction Level:

Dr. Hultgren of the DOE site Office was highly satisfied with the program results.

ITEM 32

Program/Project Title: Program 42, National Multimodal Commodity and Passenger Flow Studies

Summary Program/Project Description:

The U.S. Bureau of the Census (Census) was conducting a national commodity flow survey (CFS) in cooperation with the Department of Transportation (DOT). For a sample of shipments, the CFS was to report commodity and selected shipment attributes, origin, destination, and the combination of modes used but was not intended to report distances shipped. The object of this project was to estimate these shipment-specific distances. This was done by simulating actual routes over a network representation of the transportation system to provide the DOT and the Census with resultant distances for all possible mode combinations between Census-supplied sets of origin-destination pairs.

Responsible Lead ORNL Organization:

Center for Transportation Analysis, Energy Division

Sponsoring Organization:

Federal Highway Administration, U.S. Department of Transportation

Sponsor/Customer Satisfaction Lovel:

Sponsor/customer satisfaction was high.

ITEM 33

Program/Project Tite: Program 11, Panama Canal Operating Characteristics and Capacity Evaluation Study (PC OCCES) 
Summary Program/Project Description:

The Commission for the Study of Alternatives to the Panama Canal contracted with TAMS Consultants, Inc., to perform the OCCES. The study considered the existing canal, proposed improvement to the existing canal, and a proposed sea level canal. Overall, approximately 19 different canal configurations were evaluated. The project was conducted in two phases, the first of which was completed in FY 1992. In Phase I, the alternative canal improvement projects were prescreened, to reduce them to three or four projects, which were then analyzed in greater detail in Phase II. At the request of TAMS Consultants, Inc., the Oak Ridge National Laboratory (ORNL) Center for Transportation Analysis provided assistance in developing computer simulation models for use in the project. ORNL was responsible for modeling both canals with locks and the sea level canal.

Responsible Lead ORNL Organization:

Center for Transportation Analysis, Energy Division

Sponsoring Organization:

TAMS Consultants, Inc.

Sponsor/Customer Satisfaction Level:

Sponsor/customer satisfaction was high.

\section{ITEM 34}

Program/Project Title: Intelligent Vehicle Highway Systems (IVHS) Federal Highway Administration (FHWA) Completed Technical Work Requests

\section{Summary Program/Project Description:}

Under Department of Energy Project Number 1883-E020-A1, the Oak Ridge National Laboratory is conducting a number of research, development, and analysis activities in support of the FHWA's IVHS Program. These activities include the development and definition of technical approaches; the identification of research needs and program priorities; the evaluation of research proposals and ongoing research projects; the implementation of preliminary analyses and reviews; the organization and administration of conferences and professional forums; the development and testing of system prototypes; the promotion of industry, government, and academic partnership; and the organization of common data and information resources. 
Listed below are eight Technical Work Requests (TWRs) that have been successfully completed under the IVHS Project and have achieved a high level of sponsor satisfaction during FY 1992 and FY 1993 (the total budget for these completed TWRs is $\$ 490 \mathrm{~K})$.

- Assessment of benefits from In-Vehicle Navigation Systems (TWR 1),

- Participation in IVHS America Activities (TWR 3),

- Development of Evaluation Procedures for IVHS Projects (TWR 4),

- MAXBAND Signal Optimization Program (TWR 5),

- Fuel Consumption and Emission Study Plan (TWR 8),

- Cost Estimates for Near-Term Deployment of ATMS (TWR 9),

- Benefits of Traffic Models (TWR 10), and

- Feasibility of ATMS/ATIS Traffic Control Center Simulator (Phase 1: General Assessment) (TWR 11).

Responsible Lead OANL Organization:

Center for Transportation Analysis, Fusion Energy Division

Sponsoring Organization:

DOE-FHWA

Sponsor/Customer Satisfaction Level:

The sponsor/customer was very satisfied.

ITEM 35

Program/Project Tite: Federal Emergency Management Agency (FEMA) Integrated Management and Economic Analysis System DOE-IA No. 1457-1675-A1; FEMANO-EMW. 89-E-3138

\section{Summary Program/Project Description:}

The National Infrastructure System Regional Impacts Module is a regional economics modeling and data management package that links facility specific information and region/sector aggregate data in a common data structure such that regional economic impact assessment arising from specific facility or diffuse aggregate causes can be calculated. The package consists of software that provides a user interface, a set of programs that comprises the basic RIM language, and a reference data file from the County Business Patterns.

The system provides consistent national and regional/sectoral economic assessment capability in an easy-to-use personal computer environment. The 
major focus in the development project was damage assessment, but the system

is general and can be used for any linear economic assessment process.

Responsible Lead ORNL Organization:

FEMA

Sponsoring Organization:

Funded under interagency agreement by the FEMA at the Oak Ridge National Laboratory under budget and reporting code 42-W167502

Sponsor/Customer Satisfaction Level:

The sponsor/customer was satisfied.

ITEM 36

Program/Project Title: Single-Family Study of the National Weatherization Evaluation

Summary Program/Project Description:

An analysis was completed of the energy savings and cost-effectiveness of the nation's largest conservation program-the Department of Energy's (DOE) lowincome Weatherization Assistance Program. Because the program is implemented by more than 1000 local agencies in $\mathbf{5 0}$ states and the District of Columbia, the evaluation required an elaborate sampling design and an extensive amount of data. Ultimately, information was collected on a sample of 14,971 single-family and small multifamily dwellings weatherized by 368 local agencies and a matched sample of 4796 control homes. Energy consumption data were collected from several hundred utilities, and local climate data were compiled for the three-year study period.

Responsible Lead ORNL Organization:

Energy Division

Sponsoring Organization:

DOE-EE

Sponsoring/Customer Satisfaction Level:

The sponsor/customer was highly satisfied. As a result of the preliminary findings of this evaluation, DOE has already initiated a major technology transfer activity 
designed to bridge the gap between the state of the practice and the state of the art in low-income weatherization. In addition, DOE has proposed two new major initiatives for FY 1994 dealing with the weatherization of mobile homes and the initiation of innovative demonstration projects in the South.

\section{ITEM 37}

Program/Project Titte: Advanced Surfaces for Vertical and Horizontal-Tube Absorbers; contract No. 5089-243-1884

\section{Summary Program/Project Description:}

The Gas Research Institute is supporting an ongoing project at the Oak Ridge National Laboratory (ORNL) to advance the state of the art in the design of fallingfilm absorbers. This project involves a combined experimental and analytical approach to the formulation and validation of an absorber design code. Work was completed on a vertically oriented absorber, and an extension of similar work is ongoing for the design of horizontal-tube, aqueous, lithium bromide falling-film absorbers. The prediction of absorber performance is still poorly understood. Nonequilibrium thermodynamic conditions, uneven flow distribution and wetting, and uncertainties associated with noncondensibles and with enhancement techniques make empirical design approaches unavoidable. Benefits for the additional work will be a reduction of development costs, increased understanding wrought by new analytical techniques, and the conception of innovative absorber configurations.

\section{Responsible Lead ORNL Organization:}

DOE's Office of Building Technologies as directed by ORNL's Energy Division

\section{Sponsoring Organization:}

Gas Research Institute

\section{Sponsor/Customer Satisfaction:}

The Gas Research Institute let additional funding for research on horizontal absorbers.

ITEM 38

Program/Project Tite: Analysis of Energy Impacts and Net Contribution of Chlorofluorocarbon (CFC) Alternatives to Global Warming Potential 


\section{Summary Program/Project Description:}

The objective of this study was to evaluate the relative energy efficiencies, associated $\mathrm{CO}_{2}$ emissions, and net global warming potential of hydrochlorofluorocarbons, hydrofluorocarbons, and other available technology options in key energy-related CFC-applications areas on an international basis. The results are documented in a final report. Summaries of the results are included in three Technology Assessment reports prepared by the United Nations Environment Programme for the 1992 Montreal Protocol revision.

Responsible Lead ORNL Organization:

Building Equipment Research Program, Energy Division

\section{Sponsoring Organization:}

Alternative Fluorocarbons Environmental Acceptability Study and DOE-OBT

\section{Sponsor/Customer Satisfaction Level:}

The sponsor/customer was highly satisfied. The report was completed to the sponsor's satisfaction and on schedule despite the large volume of peer review comments to be resolved. The total equivalent warming impact concept developed under the project has become part of the lexicon of the worldwide CFC alternatives scientific and policy-making community. Sponsors approved additional funding to expand the study to include nontraditional refrigeration and insulation technologies.

ITEM 39

Program/Project Tite: Experimental Study of a Liquid Over-Feeding Mobile Air Conditioning Systems

\section{Summary Program/Project Description:}

The liquid over-feeding (LOF) concept allows $100 \%$ use of the evaporator while the high-pressure liquid is subcooled simultaneously. LOF increases the cooling capacity and system coefficient of performance (COP), and it improves the compressor reliability by lowering the discharge gas pressure and temperature. An LOF mobile air conditioner was built and tested in the two-room environmental chamber at various ambient temperatures and simulated vehicle speeds. The LOF System showed a $20 \%$ improvement in system performance in terms of cooling capacity and system COP. The results can be applied to electrical vehicle airconditioning systems. 
Responsible Lead ORNL Organization:

Thermal and Environmental Control Technology Group, EER Section, Energy Division

Sponsoring Organization:

DOE Office of Transportation Technology

Sponsor/Customer Satisfaction Level:

The sponsor/customer was highly satisfied.

ITEM 40

Program/Project Title: NC Audit Field Test

Summary Program/Project Description:

This field test was undertaken to measure the performance of a newly developed, advanced, residential energy conservation measure, selection technique against the technique used in North Carolina's current state weatherization program. A second goal of the field test was to provide important feedback from typical users that could lead to valuable improvements in the technique to benefit future users. Household energy use was measured in 120 North Carolina households along with weather data over approximately two years. Weatherizations (i.e., retrofits) were installed in the middle of this period. Results indicate that the new technique increased heating energy savings almost $50 \%$ over that achieved through standard weatherizations, did not increase costs, produced recommendations that led to substantial improvements in the technique, and warranted only a few changes to incorporate the new technique into an existing weatherization program.

Responsible Lead ORNL Organization:

Energy Division, Existing Buildings Research Program

Sponsoring Organization:

DOE-EE

Sponsor/Customer Satisfaction Level:

The sponsor/customer was very pleased to see that significant performance increase was achieved by the advanced technique and that the technique could easily be implemented into an existing program. Success of the test has led to 
state-wide implementation of the advanced technique in North Carolina since project completion and the expansion of the technique to national application (i.e., the Weatherization Assistance Program National Energy Audit).

ITEM 41

Program/Project Title: National Energy Audit (NEAT)

Summary Program/Project Description:

This project involved the development of a low-income residential energy audit tool for use in the Department of Energy's (DOE) Weatherization Assistance Program capable of selecting cost-effective energy conservation measures to install in homes qualifying for this federally funded program. The audit is in the form of a computer program that tailors retrofits to the specific house described by the user. It meets the most stringent regulations set forth by the Weatherization Assistance Program. The program was field-tested in North Carolina.

Responsible Lead ORNL Organization:

Energy Division, Existing Buildings Research Program

Sponsoring Organization:

DOE, Weatherization Assistance Program

\section{Sponsor/Customer Satisfaction Level:}

NEAT was introduced to audiences nationwide through eight presentations during FY 1993. Sponsors were pleased with the training provided to representatives of over 43 states at a recent national conference. Although formally introduced only during the summer of 1993, the program is already being used by agencies throughout five states; a minimum of 13 additional states are to begin implementation in FY 1994. Though not yet officially released to the public, at least two major utilities are using NEAT in their low-income weatherization programs.

ITEM 42

Program/Project Titte: Arizona Exterior Wall Insulation Field Test

\section{Summary Program/Project Description:}

A field test involving eight single-family houses was performed in Phoenix, Arizona, to evaluate the potential of reducing air-conditioning electricity consumption and demand by insulating their exterior masonry walls. The field test also helped develop and refine the installation technique. A modeling effort was performed in 
parallel with the field testing to help evaluate field-test results and to extrapolate results to other U.S. southern climates.

Respcrnsible Lead ORNL Organization:

Energy Division, Existing Buildings Research Program

Sponsoring Organization:

DOE-EE

\section{Sponsor/Customer Satisfaction Level:}

The sponsor is quite pleased with the effort extended on this project, the interaction with utility and state organizations that occurred, and the resulting exposure it has received. The project received an award from the State of Arizona Department of Commerce, resulted in journal publications being presented at three conferences, and will be featured in a future issue of CADDET magazine, in addition to appearing as a lead article in The Knoxville News-Sentinel. A project poster was selected for use in a possible White House briefing by Secretary O'Leary. The project has received the attention of the DOE Technology Transfer Program.

ITEM 43

Program/Project Titte: Installatior Envelope Research Center

Rotatable Climate Simulator in the Building

\section{Summary Program/Project Description:}

This project involved the complete overhaul of a large Calibrated Hot Box donated to the Oak Ridge National Laboratory (ORNL) by Dow Chemical, U.S.A. The box was converted to a guarded hot box and given a state-of-the-art data acquisition system and equipped with automated controls for conducting 24-h unmanned data collection. The climate chamber was modified to simulate wind speeds of 15 inph-a feature that makes this box a one-and-only device. It can be used to test skylights according to a National Energy Strategy-required Fenestration Rating Protocol. The work was accomplished entirely with an in-house team representing four ORNL divisions. The market value of this device is approximately $\$ 1.75$ million and cost the Department of Energy less than $\$ 500,000$. This unique experimental device has given ORNL considerable attractiveness to potential CRADA partners. In fact, in FY 1994 two outside contracts will be signed that will utilize this one-of-akind research tool. 
Responsible Lead ORNL Organization:

Energy Division

Sponsoring Organization:

DOE Office of Building Technology

Sponsor/Customer Satisfaction Level:

Peter Scofield, DOE project manager, was highly pleased. This accomplishment was highlighted in several internal reports at DOE Headquarters.

ITEM 44

Program/Project Title: Electromagnetic Pulse Research on Electric Power Systems

Summary Program/Project Description:

A nuclear detonation at high altitudes (above $40 \mathrm{~km}$ ) produces a strong electromagnetic pulse (EMP) on the order of tens of kilovolts per meter called high-altitude EMP (HEMP), which is not accompanied by other nuclear weapon effects such as heat and shock waves. A late-time quasi-static wave on the order of volts per kilometer follows the early time pulse. In 1983 DOE formulated a research program to develop the models and data necessary to assess the effects of HEMP on electric power systems. The program was completed in 1992. A comprehensive HEMP assessment methodology was developed and was tested by application to an actual utility power system. Models for HEMP interaction analysis were developed and used in parametric studies of induced surges in overhead and buried power and control lines. Improvements in the coupling models to account for lightning shield wires, line configurations, and ground wires continued during the research period. Experiments were conducted to develop a database required by the HEMP assessment methodology. Electromagnetic interference data in substations caused by switching operations were used to develop models for analysis of substation controls and protective relays. This tenyear project is summarized in an Oak Ridge National Laboratory report, ORNL6708, January 1993.

Responsible ORNL Lead Organization:

Energy Division

Sponsoring Organization:

DOE Office of Energy Management 
Sponsor/Customer Satisfaction Level:

The sponsor/customer was very satisfied.

ITEM 45

Program/Project Tite: Attic Natural Convection Mitigation

Summary Program/Project Description:

To gain a unique insight into the thermal performance of residential attics, an attic test module simulating typical residential construction was built at the Building Envelope Research Center for use in the Large-Scale Climate Simulator. These tests have generated dozens of cases of in-service performance of attic insulation under simulated winter conditions. A significant finding has been that the most common attic insulations do not perform as well as would be expected from the results of small-scale tests that are routinely done by the insulation industry. This loss, due to natural convection through the insulation, causes a more than $50 \%$ reduction in effective thermal resistance as shown by measurement.

This work led to revision of the Minnesota State Energy Code, spurred development of a new American Society for Testing and Materials standard, and won the prestigious honor of being one of Popular Science's "10 Greatest Achievements in Science and Technology" in 1992.

Responsible Lead ORNL Organization:

Energy Division

Sponsoring Organization:

DOE Office of Building Technology; Attic Seal, Inc.; Manville; Cellulose Insulation Manufacturer's Association

Sponsor/Customer Satisfaction Level:

The sponsor/customer insisted we attend the Popular Science Award Ceremony last December in Central Park.

ITEM 46

Program/Project Titte: Final Supplemental Environmental Impact Statement for the United States Antarctic Program 


\section{Summary Program/Project Description:}

In 1980 the National Science Foundation (NSF) published a Programmatic Environmental Impact Statement (PEIS) on the U.S. Antarctic Program (USAP). The PEIS described the program and evaluated programmatic activities for a five-year period starting in 1980. The PEIS was reprinted and redistributed with no changes in 1984. Many changes subsequently occurred in the activities of the USAP, and NSF decided to prepare a Supplemental Environmental Impact Statement (SEIS) on the USAP in accordance with Executive Order 12114-Environmental Effects Abroad of Major Federal Actions. The purposes of the SEIS were (1) to update baseline descriptions of the program and of the Antarctic environment presented in the PEIS and (2) to evaluate the significance of potential environmental impacts of proposed program actions and alternatives.

Responsible Lead ORNL Organization:

Energy Division, Environmental Analysis and Assessment Section

Sponsoring Organization:

NSF, Office of Polar Programs

Sponsor/Customer Satisfaction Level:

The sponsor/customer was very happy with ORNL's response and the document. Very complementary comments were received on the SEIS, and the document has been used as an example of "how to" prepare EISs in a commercially taught National Environmental Policy Association course.

ITEM 47

Program/Project Titte: Environmental Impact Statement on Modifications to the Operation of the Lower Mokelumne River Project

\section{Summary Program/Project Description:}

The existing hydroelectric project is a multipurpose multireservoir system licensed to the East Bay Municipal Utilities District (EBMUD); it provides the municipal water supply to Oakland and the East Bay area of California. Chinook salmon and steelhead trout have experienced recent population declines and fish kills in the Lower Mokelumne River associated with discharges from Comanche Dam and other stresses in the river, such as irrigation diversions and acid mine drainage. The California Department of Fish and Game and the California Sporttishing Protection Alliance asked the Federal Energy Regulatory Commission to investigate and to correct fishery impacts in the river. A wide range of potential

\section{C-35}


mitigation actions were identified during the scoping process for this assessment. All appropriate alternatives were evaluated in terms of benefits to the anadromous fishery resources and the costs of each action to EBMUD's water supply system.

Responsible Lead ORNL Organization:

Energy Division, Environmental Analysis and Assessment Section/Environmental Sciences Division

Sponsoring Organization:

Federal Energy Regulatory Commission

Sponsor/Customer Satisfaction Level:

In response to an inquiry by the Department of Energy Oak Ridge Operations staff, the sponsor/customer indicated $100 \%$ satisfaction.

ITEM 48

Program/Project Title: Foothills Parkway Segment 8-D Environmental Report

Summary Program/Project Description:

The Environmental Analysis and Assessment Section prepared an environmental report that contained data and analyses on potentially significant issues for the construction and operation of Section 8-D of the Foothills Parkway bordering the Great Smoky Mountain National Park. This project included analyses of water quality, geological, and soils issues related to previous Oak Ridge National Laboratory (ORNL) experience with watershed analyses and effects of acidic materials on water resources.

Responsible Lead ORNL Organization:

Energy Division, Environmental Analysis and Assessment Section

Sponsoring Organization:

National Park Service

Sponsor/Customer Satisfaction Lovel:

The sponsor/customer was very pleased. 
ITEM 49

Program/Project Title: Widely Deployable Low-Cost Radiometer for the ARM Extended Observing Stations

Summary Program/Project Description:

The objective of this project, which was completed in FY 1993, was design, development, and demonstration of a customized pointing shortwave/near-infrared radiometer and related mathematical techniques that can be applied to the resulting radiometric data to infer concentrations of atmospheric gaseous constituents and sizes of suspended particulate matter.

Responsible Lead ORNL Organization:

Instrumentation and Controls (I\&C) Division

Sponsoring Organization:

DOE, Carbon Dioxide Research Program, Office of Health and Environmental Research

\section{Sponsor/Customer Satisfaction Level:}

The sponsor/customer apparently thought that our technical design was good but that our costs were too high in relation to other organizations to whom the sponsor can turn for work of a similar nature (principally, these are universities having active programs in the field of atmospheric research and federal agencies such as the National Aeronautics and Space Administration, which does not charge DOE for the time of their principal investigators). However, if the sponsor had been highly satisfied, we would not have suffered the 2nd- and 3rd-year funding cuts that occurred.

\section{ITEM 50}

Program/Project Titte: Sonar Signal Analysis System-Element-Screening Software

\section{Summary Program/Project Description:}

The element-screening software package provides an efficient mechanism for an acoustician to examine data from several related sensors (i.e., elements of an array). The element-screening software package provides a root mean square level display, a K-Omega display (i.e., beam-formed data presented as a wavenumber vs frequency display), a time series display, and an relative delay table. Using real-time software techniques, Instrumentation and Controls engineers minimized the processing time to produce a near real-time analysis tool kit. 
Responsible Lead ORNL Organization:

Instrumentation and Controls Division

Sponsoring Organization:

Carderock Division/Navel Surface Warfare Center (CD/NSWC)

Sponsor/Customer Satisfaction Level:

Sponsor/customer satisfaction was high. This software package operated at near real-time (which was faster than CD/NSWC had expected).

ITEM 51

Program/Project Ttte: Acoustic Measurement Facilities Improvement Program, Phase II (AMFIP II) High-Gain Array, Low-Frequency Electronics, Design/Fabrication/Testing

Summary Program/Project Description:

This program consisted of design, fabrication, and testing of signal conditioning, digitization, data telemetry, and data-processing electronics for underwater and shipboard use in AMFIP II. These three sets of electronics, each containing over 200 printecj-circuit assemblies (plus spares), will acquire and deliver signal from over 950 hydrophones to new and existing shipboard data analysis systems. This system provides a wider dynamic range and wider frequency coverage than existing phased-array sonar systems.

Responsible Lead ORNL Organization:

Instrumentation and Controls Division

Sponsoring Organization:

Carderock Division/Navel Surface Warfare Center

Sponsor/Customer Satisfaction Level:

The sponsor/customer was satisfied. (This is a subtask from a much larger program that will not be completed until fall, 1994.)

ITEM 52

Program/Project Title: Development of Mass Flow Controller Testing Apparatus 


\section{Summary Program/Project Description:}

The goal of this project is to improve mass flow controllers to support the international competitiveness of the U.S. semiconductor industry. The tasks to support this goal include development of industry-wide standardized test methods for mass flow controllers, design and fabrication of a mass flow controller development laboratory, generation of baseline data from approximately 100 mass flow controllers, and development of a primary standard for mass flow usable with hazardous process gases.

Responsible Lead ORNL Organization:

Instrumentation and Controls Division

Sponsoring Organization:

SEMATECH (WFO)

Sponsor/Customer Satisfaction Level:

Sponsor/customer satisfaction was high.

ITEM 53

Program/Project Titte: Multichannel Scaler Instrument

\section{Summary Program/Project Description:}

A multichannel scaler function, necessary for signal processing of the monitor, was successfully implemented as an application-specific integrated circuit by the Instrumentation and Controls (I\&C) team. A microcontroller-based instrument was designed and constructed to support the operation of the multichannel scaler chip. Custom software was developed in coordination with the design of the chip and the microcontroller for programmable control, user interface, and communication. This demonstration gave impetus to the this year's work in which the microcontroller-based multichannel scaler was to be incorporated into a complete uranium analysis system packaged for field use.

Responsible Lead ORNL Organization:

Instrumentation and Controls Division

Spcrsoring Organization:

DOE-DP (Y-12 Plant Development) 
Sponsor/Customer Satisfaction Level:

Sponsor/customer satisfaction wash high.

ITEM 54

Program/Project Title: Portable Uranium Monitor

\section{Summary Program/Project Description:}

Members of the Oak Ridge National Laboratory Instrumentation and Controls Division (I\&C) were requested to continue with the development and construction of a portable uranium monitor prototype for testing aqueous samples in the field. The purpose of this monitor is to analyze aqueous sources, such as streams and wells, for undesirable levels of uranium. The monitor was developed incorporating the multichannel scaler instrument developed in the previous fiscal year. Most of the hardware is custom designed and fabricated. The software system was developed in-house as well.

Responsible Lead ORNL Organization:

Instrumentation and Controls Division

Sponsoring Organization:

DOE-DP (Y-12 Plant Development)

Sponsor/Customer Satisfaction Level:

Sponsor/customer satisfaction was high.

ITEM 55

Program/Project Tite: Rack-Mounted Aqueous Uranium Analyzers

\section{Summary Program/Project Description:}

Members of the Oak Ridge National Laboratory Instrumentation and Controls Division (I\&C) were requested (1) to complete the construction of a uranium monitor prototype (Unit 1), (2) to revise the layout and fabricate a second monitor (Unit 2), and (3) to layout and to fabricate a prototype for an airborne uranium monitor. Another significant portion of the work for both types of monitors was the development of customized software systems required for control of the monitor together with data acquisition and analysis. These monitors are to provide on-line, continuous monitoring of waste water, process streams, other aqueous sources (e.g., aqueous uranium monitors) of uranium. It was determined that self- 
contained instruments could be built to perform on-line analysis with largely off-theshelf components. Some parts had to be designed and fabricated in-house. After fabrication and general instrument checkout in I\&C, the monitors were sent to the Y-12 Plant to be tested and adjusted under closer-to-real-world conditions.

Responsible Lead ORNL Organization:

Instrumentation and Controls Division

Sponsoring Organization:

DOE-DP ( $\gamma-12$ Plant Development)

Sponsor/Customer Satisfaction Lovel:

Sponsor/customer satisfaction was high.

ITEM 56

Program/Project Tite: Four-Plant Medical Computer System Upgrade

Summary Program/Project Description:

The Four-Plant Medical Computer System collects medical data from the Health Centers at the three Oak Ridge plant sites and the Paducah Health Center. The system provides an information and reporting system for individual patients, surveys, incidence rates and occurrences in the population of Energy Systems. The upgrade effort consisted of replacing fourteen-year-old computer equipment a with new dual computer system and a new operating system in order to eliminate any downtime for the Health Centers. The development, integration, conversion, and testing were completed within schedule and within budget.

Responsible Lead ORNL Organization:

Instrumentation and Controls Division

Sponsoring Organization:

Energy System Health Centers

Sponsor/Customer Satisfaction Level:

Sponsor/customer satisfaction was high. 
ITEM 59

Program/Project Title: Coors Machine Vision Inspection System-Phase I

\section{Summary Program/Project Description:}

The Coors Ceramics Company in Grand Junction, Colorado, produces thick-film ceramic substrates for microelectronic circuits. The quality control of this product during manufacturing is highly dependent on human inspectors who perform quality measurement tasks. The verification of dimensional integrity is performed on a small sampling of a product batch, while characterization of surface quality (e.g., the presence of impurities, chips, and blisters) is tediously performed by hand and requires several inspectors. The Instrumentation and Controls Division (I\&C) of Energy Systems is providing the Coors Ceramics Company with the necessary technology and experience to automate this inspection task through the application of machine vision technology. The benefits include a larger product sampling rate, a nonsubjective and repeatable measurement of surface quality, and an automated product classification and sorting scheme that allows for the flexible categorization of parts.

Responsible Lead ORNL Organization:

Instrumentation and Controls Division. Advanced Computation and Machine Vision Group (ACMV)

Sponsoring Organization:

Funded by DOE-DP under CRADA Y-12 92-0078

\section{Sponsor/Customer Satisfaction Level:}

The sponsor/customer is extremely satisfied with Phase $I$ and all interactions provided by the I\&C-ACMV team.

\section{ITEM 58}

Program/Project Title: Image Transrnission Network (ITN) Image Capture System Prototype

\section{Summary Program/Project Description:}

The object of this project was to develop a high-resolution image capture system prototype for the Federal Bureau of Investigation (FBI) to generate digital images of criminal fingerprint cards. The ITN Image Capture System was required by the FBI to generate test data needed to validate concepts associated with the FBl's multimillion dollar modernization effort known as the Integrated Automated 
Fingerprint Identification System. The ITN Image Capture System was developed for digitizing, compressing, displaying, and storing images of fingerprint cards on magnetic media.

Responsible Lead ORNL Organization:

Instrumentation and Controls Division

Sponsoring Organization:

Federal Bureau of Investigation

Criminal Justice Information Services Division

J. Edgar Hoover Building

Washington, D.C.

Sponsor/Customer Satisfaction Level:

Sponsor/customer satisfaction was high. The FBI was very pleased with the performance of the ITN Image Capture System. The success of the ITN Image Capture System resulted in a follow-on request by the FBI to develop a Low-Speed Fingerprint Image Capture System prototype.

ITEM 59

Program/Project Title: Future Battle Laboratory/Corps Command Group Vehicle

\section{Summary Program/Project Description:}

During Operation Desert Storm the Corp Level Commanders fought the 100-h battle from the back of HumVees with the help of cellular telephones and lap-top computers. From this experience the Commander-In-Chief U.S. Army Forces Europe (CINCUSAEUR) determined that a need existed for a self-contained, autonomous mobile command and control (C2) vehicle from which a commanding general could fight and influence a war. Based on these needs, Energy Systems was invited by Future Battle Lab and CINCUSAEUR to participate in the Caravan Guard 91 exercise to develop a requirements document outlining the functional needs of the $\mathrm{C} 2$ vehicle. Based on this analysis, a command and control vehicle prototype called the Corps Command Group Vehicle was designed, developed, and deployed for evaluation.

Responsible Lead ORNL Organization:

Instrumentation and Controls Division 
Sponsoring Organization:

U.S. Army/Future Battle Laboratory

Sponsor/Customer Satisfaction Level:

Sponsor/customer satisfaction was high.

ITEM 60

Program/Project Titte: Future Battle Laboratory/Future Command and Control Vehicle Summary Program/Project Description:

The Future Command and Control Vehicle is a command, control, and communications track system prototype developed to meet the operational needs of a mobile division commander. It is based on the Bradley Fighting Vehicle chassis with a mounted, double-walled shelter housing an environmental control unit, 15k-W primary power unit, and an integrated combat suite. The two prototypes that were built were designed as a complimentary pair, each of which maintained a capability to operate as a stand-alone unit-self-contained and completely autonomous. These systems are designed to provide maximum flexibility, supporting the multitude of configurations needed for division, battalion, and special operations.

Responsible Lead ORNL Organization:

Instrumentation and Controls Division

Sponsoring Organization:

U.S. Army/Future Battle Laboratory

Sponsor/Customer Satisfaction Level:

Sponsor/customer satisfaction was high.

ITEM 61

Program/Project Title: Coastal Systems Station (CSA) MK2 Installation Box

Summary Program/Project Description:

The CSDG Group of RIS successfully completed a project for Coastal Systems Station, Panama City, Florida. This project provided the redesign and fabrication of ten each CSA MK2 Installation Boxes for engineering testing and evaluation. 
Each unit consisted of a Launch Diagnostic Control, eight cables, eight cable adapters and a separate enclosure to house the eight system interconnect cables, and eight cable adapters.

Responsible Lead ORNL Organization:

Instrumentation and Controls Division

Sponsoring Organization:

Navy Coastal System Station, Panama City, Florida

Sponsor/Customer Satisfaction Level:

The sponsor/customer was very pleased and has entered into a second Interagency Agreement. 


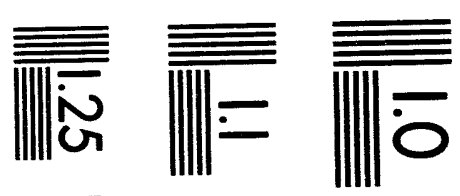

$$
\begin{aligned}
& \text { E }
\end{aligned}
$$

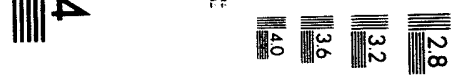

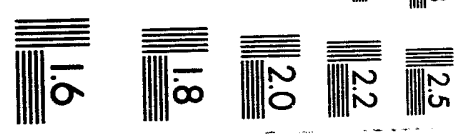



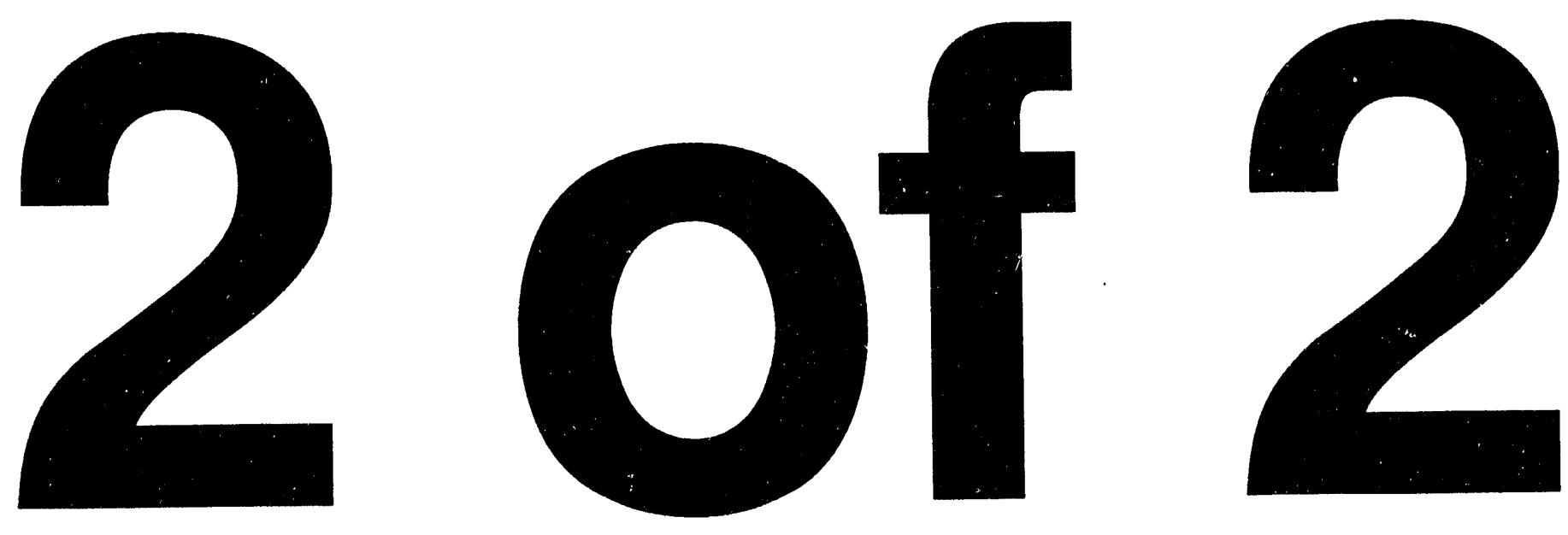
Appendix D

PERFORMANCE OF THE ORNL MATRIX MANAGEMENT SYSTEM:

SUMMARY OF RESPONSES FROM DOE HEADQUARTERS PROGRAM MANAGERS 


\section{Appendix D}

\section{PERFORMANCE OF THE ORNL MATRIX MANAGEMENT SYSTEM: SUMMARY OF RESPONSES FROM DOE HEADQUARTERS PROGRAM MANAGERS}

This appendix includes summaries of telephone conversations between the Department of Energy-Headquarters program managers and a member of the Matrix Management Upgrade Solutions Team.

Charlie Sorrell:

- Sorrell, who works with Pete Angelini, has been a Department of Energy (DOE) program manager for about two years. He said that if it were not for Angelini, he would have left his job after about two weeks. Angelini helps him immensely. They have a "wonderful working relationship."

- Funding for intermetallic alloy development cornes from several sources- one of which is Sorrell's program. Other sources of funding are managed by Ray Johnson, Mike Karnitz, and Rod Judkins at the Oak Ridge National Laboratory (ORNL). Johnson, Judkins, Karnitz, and Angelini work very well together, leveraging their funding into a coherent program.

- The DOE/Oak Ridge Organization (ORO) (Gene Hoffman) has a very close working relationship with ORNL, which Sorrell views very positively. He wishes such arrangements were in place at other laboratories. Sorrell has problems getting things done at other laboratories because of the lack of effective working arrangements with their field offices.

- Sorrell sees no conflict between the program and the line with regard to issues of clout, priority, etc. He knows Ron Bradley and Doug Craig, and has the impression that Metals \& Ceramics (M\&C) is a very customer oriented division and that the program managers get good support from the division.

- All of Sorrell's comments were very positive about the ORNL staff and organization.

Bob Schulz:

- He feels that the system works fine and that Ray Johnson does a great job. All ORNL program managers that he knows do excellent work.

- He manages a ceramic heat engine program. Has also worked with the High Temperature Materials Laboratory (HTML).

- He feels that the matrix system takes more people. We talked about this. I explained that an organization with 300 or more programs has to have some way to develop and to allocate resources. Each program cannot have its own welding 
laboratory, computers, microscopes, etc. To work without a matrix organization would be very inefficient and ineffective. Schulz accepted that logic.

- Schulz wondered whether program managers got sufficient credit and recognition for what they do. He has no firsthand data to suggest that they do not but must have heard something along this line to cause him to mention it.

Scott Richlen:

- Richlen has been at DOE for nine years. Before that, he was at the Idaho National Engineering Laboratory (INEL) for nine years. He feels that most laboratories are physically remote (and therefore have a tendency to be intellectually remote as well) from the issues of the day. The issue of today is industrial cooperation, competitiveness, and technology transfer. National laboratories cannot be in an ivory tower. Laboratories have been a long time without much oversight. Industry has a fast response time. Laboratories have to determine whether they are organized for long-term programs or to provide fast response. The laboratories need to decide on the industry cluster with which they are most compatible. The laboratories need a management structure that is fast-moving and flexible. He then described a couple of horror stories (presumably from some organization other than ORNL) where group leaders charged staff time to whatever accounts were open regardless of what projects the staff were working on.

- Any large organization has trouble locating the right people with the right knowledge. Organizations need to be able to tap into the right technical skill and talent. ORNL does this very well through Mike Karnitz (program manager in the M\&C Division). Karnitz does a very good job of meeting Richlen's needs. Karnitz is the person to ask about organizational problems within the ORNL structure.

- Richlen is generally happy with ORNL. He wants to work through verbal instructions rather than "clutter up" the system with written memos and instructions. He calls this the "Japanese system" of working with friends and people he trusts. If he has to resort to written instructions, this is usually the last step before "cutting them loose." He feels this paperless system reduces wasted motion.

- Richlen suggested that if ORNL really wants to evaluate its Matrix Management System, it should be benchmarked against some other world leader, such as Bell Laboratories.

- Richlen suggested that we ask Mike Karnitz for his opinions about ORNL matrix management. F. J. Homan called Karnitz, and here are his thoughts:

- Karnitz is not on as strong a crusade as Gene Hoffman. He feels controlling distribution of funding gives the program manager all the clout he/she needs to get staff attention. 
- Karnitz feels he can go to a group leader (GL) and give input on the performance of a principal investigator (PI). The GL will usually accept this input. However, when the $\mathrm{GL}$ is also the $\mathrm{PI}$, the section head (SH) is less likely to accept input. The SHs tend to protect the GLs.

Jim Carr:

- He is manager of Fossil Energy Materials Program.

- He is not familiar with the ORNL Matrix Management System.

- His program is very well managed by Rod Judkins.

- ORNL top management does not give his program enough attention, especially in the area of trying to get more funding. The program has been funded at the same level for the past ten years and has therefore dropped $60 \%$ in buying power. It is a small program but is very important. It is one of the only ongoing alloy development programs in the United States. This program has won five or six IR-100 Awards (not all at ORNL).

- He suggested that we talk to Rod Judkins about problems with the Matrix Management Systems.

Bill Barnett:

- He had no complaints about the ORNL Matrix Management System as practiced by $M \& C$ (which is where most of his experience with ORNL lies).

- He has had no experience yet with Doug Craig. Jim Stiegler would listen and fix problems immediately.

- He expects more of a problem when working across division lines or across plant boundaries.

- $\mathrm{He}$ is happy with the way things are working now with the Radioisotope Thermal Generator (RTG) Program. He is very happy to have Peyton Moore assigned to manage the program.

- Management gave the RTG production problems the right amount of attention to get the problems resolved. 
Jim Eberhardt:

- He is very complimentary of Ray Johnson (a program manager) and Vinod Sikka (a group leader).

- Eberhardt said that "...Ray Johnson has been spectacular. He is always responsive, well organized, neat....".

- Regarding Vinod Sikka, Eberhardt said "...he's pulled our bacon out of the fire many times, especially with the Cummins Engine Company nickel aluminide program....Some people think technology transfer is giving somebody a report and leaving it at that....The administrative aspects of technology transfer can eat you alive....Vinod has been very effective in keeping technology transfer moving forward....".

- Ray Johnson took a material that is worthless in structural applications and made it into one of the world's best ceramics.

- Program managers do not get enough kudos. Energy Systems gives awards to researchers. Where are the awards for program managers?

- "Nonresearchers get the shaft at ORNL." 


\section{Appendix E}

SUMMARY OF INFORMATION GATHERED 


\section{Appendix $\mathrm{E}$}

\section{SUMMARY OF INFORMATION GATHERED}

Over a four-month period, the Matrix Management Upgrade Solutions Team (MMUST) held biweekly meetings at which program managers from the Oak Ridge National Laboratory (ORNL) and the Y-12 Plant presented their experiences, perspectives, and concerns. Each of these presentations is documented in detailed meeting minutes that include viewgraphs and supporting materials provided by each of the presenters. Also, each MMUST member brought their personal experiences and concerns to this phase of the activity. These became an integral part of the evaluations and recommendations. This "information-gathering" phase of the MMUST effort covered a broad range of programs and projects that were generally representative of programs and projects at ORNL.

The information gathered in this phase formed a basis for the actions recommended by the MMUST. The team evaluated this information to identify (1) concerns expressed by a majority of the presenters and (2) principal areas of weakness in ORNL matrix management. Recommendations were then formulated to address these concerns and weaknesses.

A summary of the information gathered at each of the meetings follows:

June 18, 1993

Gene Hoffman, Department of Energy-Oak Ridge Operations (DOE-ORO)

There is a lack of definition of roles and authority of program/project managers in Energy Systems.

In general, the authority of program/project managers at ORNL is inadequate relative to responsibilities.

Strengthened matrix management would give ORNL a competitive advantage.

Roy Cooper, Radioisotopes Thermoelectric Generators Program

Highly visible problems in this program were the principal source of DOEORO criticism of ORNL/Energy Systems program/project management.

The principal breakdown in this program occurred across plant lines $(Y-12$ Plant support to an ORNL program).

Managers at the Y-12 Plant did not consider the ORNL program manager (viewed as a scientist) as a credible source of criticism of Y-12's approach to a nonweapons manufacturing job. 
In a "cross-plant" Energy Systems matrix, the point of commonality in the management chain of command is at too high a level to be effective in solving matrix interface problems for a program/project (e.g., in this case, the first point of management commonality was the President of Energy Systems).

July 2. 1993

Ron Bradley, management of multiple programs in the Metals and Ceramics (M\&C) Division

The M\&C Division has used matrix management successfully for over fifteen years. While it is the core of their operating philosophy, they recognize weaknesses and issues that, if corrected, could substantially strengthen their execution of programs and projects.

The ORNL promotion/award system does not encourage our capable people to become program managers.

It is increasingly difficult to recruit program/project managers.

There are continuing problems in obtaining appropriate promotions and salary increases for program managers.

Statistics indicate that the technical career path at ORNL provides a better opportunity for career growth and advancement than the program/project management path.

July 16, 1993

Bob Mason, management of a nonresearch and development (R\&D), supportservice-type program-the Energy Systems Waste Management Program

These programs are under continuous scrutiny, review, and monitoring by DOE. Problems become very visible very quickly.

The Waste Management and Remedial Actions Division (WMRAD) at ORNL is in the ORNL line organization and under a K-25 Site program organization. Grade level and other promotional criteria are not necessarily consistent across plant lines.

Program/project manager grade levels in this division appear to be low, and sometimes mixed, relative to responsibilities. 
Program/project manager levels and salaries appear to be lower in support service organizations (e.g., WMRAD and Plant and Equipment than for equivalent positions in R\&D organizations.

August 13,1993

Paul Haubenreich (retired)-Large Coil Program

Initial funding for the program was too low. This caused ongoing problems for the program.

Initial staffing for the program matrix was difficult because ORNL management was not convinced about the program and did not take it seriously. Staffing was an up-hill battle for the program manager.

Enthusiasm for, and commitment to, this program was a bottoms-up process. Lack of strong ORNL support and commitment from the outset was a negative factor.

This program was a matrix and utilized many technical staff from ORNL. Paul has good memories of the people; the bad experiences were with organizational barriers. The program was a success in spite of these internal organizational barriers.

The program was constrained to the in-house engineering organization for engineering support. The program manager had little say in the selection of engineering staff assigned to the program. The engineering staff did not grasp the developmental nature of the program and the need to work interactively with the program team. The prevailing attitude was: "We are not providing people to work for you; tell us what you want and we will design it our way under the direction of our supervisors." The program manager did not have sufficient authority to correct this and had to "work around" the problem.

\section{August 27. 1993}

Jim Hannah, Future Armor Rearm System (FAP,S) Project

This highly successful project has led to dramatically increased funding in this program area.

The FARS project utilized a broad matrix of resources from ORNL, the Y-12 Plant, and the K-25 Site. Ten to twenty percent of the project is line staff. The balance is matrixed. This matrix has worked well, as is evidenced by the very successful FARS Project. 
A proactive approach to teamwork has been an important factor. A team approach and team involvement from the outset are key issues. The "team" works together on specifications, design, fabrication, and testing. The team has ownership of the whole process and any problems along the way. They work together to address and solve problems. There is no room for "finger pointing."

Communication is a critical issue, both within the matrix organization and with the customer. Jim stressed effective communication as a basis for successful program and project management.

A mixture of job codes was evident in the staff managing this program. Job code differences has not been a significant issue. Individual "people skills" and management capabilities are much more important.

A general rule Jim uses in setting commitments for matrix resources is to confirm each commitment with management at least two levels above the individual who will be working with the project.

If problems occur with an individual in the matrix, Jim generally works out the problem with that individual's supervisor.

Jim and his team have typically not been asked to provide input to the performance evaluation of individuals matrixed to the program. Howyever, Jim feels that this should be done.

If a supporting organization wants to handle its part of the work independently, and not operate as part of the team, Jim's advice is "never accept that." Either convince them of the necessity and benefits of an integrated team or go find an alternate resource to do that work.

\section{September 10,1993}

Sam Murphy (Y-12 Plant), Seawolf Propulsor Project Prototype

Centered at the Y-12 Plant, this project matrixed into the technical staff at ORNL.

Project managers must "assume" full authority; the authority needed is not vested by the title, position, or Energy Systems.

A project manager must challenge and work around existing "systems" as needed to get the job done. 
Carefully select your matrix team. Select the best technical people, do not accept less, and make them accountable for results and commitments.

Always provide input to the annual performance review of people matrixed to the project, whether it is requested by their line management or not. Discuss it directly with their line management if possible.

Jim Lawson, ORNL Engineering

The Engineering organization is structured to support and to respond to large engineering projects (e.g., line item and general plant projects).

Engineering generally works with a project structure that is defined and required by DOE orders.

Engineering tries to support R\&D projects and programs but is often caught between staffing level limitations and project (e.g., line item project) priorities.

While R\&D projects and programs at ORNL often have no alternative to the Engineering organization, the engineering discipline structure cannot always respond to program/project requests for assignment of "the best" specific people.

ORNL Engineering has initiated a new element in its organization called a "small projects group." This group will be able to respond to small project using a graded approach and is intended to be an improvement for R\&D programs and projects.

\section{October 1. 1993}

Margaret Morrow (Y-12 Plant)-via a discussion with Frank Homan

Strong communications are essential in program/project management.

It is more difficult to communicate and to work across site boundaries than within a site. Styles are different across site boundaries, vocabularies are different, and priorities are different.

ORNL program managers are generally more mature than those at the $Y-12$ Plant.

Personal relationships with the line organizations are very important and must be carefully developed if they do not already exist.

It is important to get understanding and agreement that the program/project manager is the boss and that the line organizations are providing a service. 
General Discussions

When program/project activities were reviewed by the team, it became apparent that two types of programs/projects are conducted at ORNL. One type is major programs/projects sought by senior management, such as the Advanced Neutron Source and the Waste-Handling and Packaging Plant. The second type is the programs/projects initiated from the "bottom up" by staff members.

In the case of the major programs/projects, senior management is involved in periodic reviews and receives regular status reports. Thus, problems can be identified as they develop and senior management will be aware of the need for corrective actions before the problems mature and become visible. However, for the smaller programs/projects, it appears that senior management is not regularly involved in project reviews and may or may not review regular status reports. For these programs/projects, developing problems may not be "bucked up" the system for senior management attention before the problems become visible to an external customer.

Programs/projects also fall into two generic categories: R\&D and general ORNL programs/projects (e.g., waste management or environmental restoration). Many of the general ORNL programs/projects are associated with, and funded by, major DOE programs and are large budget, multiyear efforts. These high-visibility programs/projects are having their reporting systems restructured to provide DOE Headquarters with more information on the status of the program/project through the "Program Tracking System." This allows DOE to identify problems and to take action before significant program/project impacts occur. Part of the reason for this change is DOE's perception that Energy Systems senior management has not controlled programs/projects adequately, leading to problems requiring DOE-ORO office intervention.

ORNL management overview of programs/projects related to waste management and environmental restoration is intense, consisting of internal reviews by senior management through monthly presentations for each program/project element as well as monthly trend analysis and reports. This level of overview is not feasible for all programs/projects at ORNL, yet external customers, particularly DOE, do monitor the programs/projects in detail. This indicates the need for an improved, more uniform, and better communicated system at ORNL to alert senior management to emerging problems and needed actions before the problems become significant issues with the customer. 
INTERNAL DISTRIBUTION

1. B. R. Appleton, $4500 \mathrm{~N}, \mathrm{MS} 6240$

2. J. B. Ball, 6000 , MS 6369

3. V. Baylor, 9113, MS 8206

4. B. A. Berven, 4500 S, MS 6124

5. R. M. Bishop, $4500 S$, MS 6103

6. S. G. Bly, $4500 \mathrm{~N}$, MS 6251

7. R. A. Bradley, 4515, MS 6067

8. J. K. Bryson, 4500 N, MS 6219

9. J. K. Carlsmith, $4500 N, 6188$

10. R. H. Cooper, Jr., 4508, MS 6079

11. D. F. Craig, 4500 S, MS 6132

12. A. G. Croff, $4500 \mathrm{~N}$, MS 6235

13. N. H. Cutshall, K1001, MS 7172

14. L. B. Dunlap, 6206-E, MS 6396

15. M. P. Farrell, 7910, MS 6387

16. R. E. Fenstermaker, Jr., 2024, MS 6052

17. D. E. Fowler, 1505, MS 6035

18. D. Frazier, $4500 N$, MS 6198

19. W. Fulkerson, 4500 N, MS 6247

20. A. S. Garrett, Jr., $4500 N$, MS 6220

21. R. K. Genung, 4500 N, MS 6228

22. H. S. Giles, 2517, MS 6312

23. H. A. Glovier, Jr., 7917, MS 6398

24. V. M. Gray, 2517, MS 6312

25. J. L. Hammontree, 2518, MS 6323

26. J. N. Hannah, 7601, MS 6304

27. F. C. Hartman, 9207, MS 8077

28. R. W. Henderson, K-1580, MS 7595

29. J. N. Herndon, 7601 , MS 6305

30. S. G. Hildebrand, 1505, MS 6037

31. F. J. Homan, 9102-1, MS 8038

32. R. B. Honea, $4500 \mathrm{~N}$, MS 6230

33. J. E. Jones, Jr., 9201-3, MS 8063

34. K. L. Kliewer, 4500 N, MS 6203

35. M. W. Kohring, $4500 \mathrm{~N}$, MS 6256

36. F. C. Kornegay, 4500 N, MS 6275

37. E. H. Krieg, Jr., 5000, MS 6346

38. W. C. Kuykendall, 5000, MS 6346

39. W. R. Laing, $4500 S$, MS 6127
40. J. R. Lawson, 1000 , MS 6338

41. A. P. Malinauskas, K-1001, MS 7172

42. R. C. Mason, 3047, MS 6023

43. D. W. McDonald, 3500, MS 6005

44. L. E. McNeese, 3047, MS 6023

45. M. K. Morrow, 9704-2, MS 8016

46. S. M. Murphy, Jr., 9201-1, MS 8211

47. J. C. Nook, 3502, MS 6327

48. M. L. Poutsma, 4500S, MS 6129

49. C. E. Pugh, 9201-3, MS 8063

50. D. E. Reichle, $4500 \mathrm{~N}$, MS 6253

51. J. B. Richard, 7962, MS 6391

52. J. B. Roberto, 3025, MS 6033

53. M. J. Saltmarsh, 4500 , MS 6251

54. J. Sheffield, 9201-2, MS 8070

55. R. B. Shelton, $4500 N$, MS 6187

56. F. W. Shull, Jr., 4500 N, MS 6214

57. W. D. Shults, II, 4500N, MS 6182

58. C. S. Sims, $4500 S$, MS 6106

59. R. F. Sincovec, 6012 , MS 6367

60. D. N. Smith, 2518, MS 6322

61. J. O. Stiegler, $4500 N$, MS 6248

62. S. H. Stow, 1505, MS 6038

63. J. H. Swanks, $4500 N$, MS 6260

64. C. S. Travaglini, $4500 \mathrm{~N}$, MS 6261

65. A. W. Trivelpiece, 4500 N, MS 6255

66. R. I. Van Hook, 4500 N, MS 6241

67. R. C. Ward, 6025, MS 6359

68. D. A. Waters, K-1225, MS 7291

69. J. R. Weir, Jr., 4500S, MS 6134

70. C. D. West, FEDC, MS 8218

71. G. E. Whitesides, 4500 N, MS 6238

72. E. W. Whitfield, III, $4500 \mathrm{~N}, 6210$

73. H. R. Yook, 7601, MS 6305

74. Laboratory Records-RC

75-76. Laboratory Records

77. Central Research Library

78. Document Reference Section

79. ORNL Patent Office 
80. P. N. Haubenreich, 501 West Hills Road, Knoxville, Tennessee 37090

81. E. E. Hoffman, Department of Energy, Oak Ridge National Laboratory, P. O. Box 2008, Oak Ridge, Tennessee, 37831-6269

82. Office of Assistant Manager of Energy Research and Development, P. O. Box 2001, Oak Ridge, Tennessee 37831

83-84. Office of Scientific and Technical Information, P. O. Box 62, Oak Ridge, Tennessee 37831 

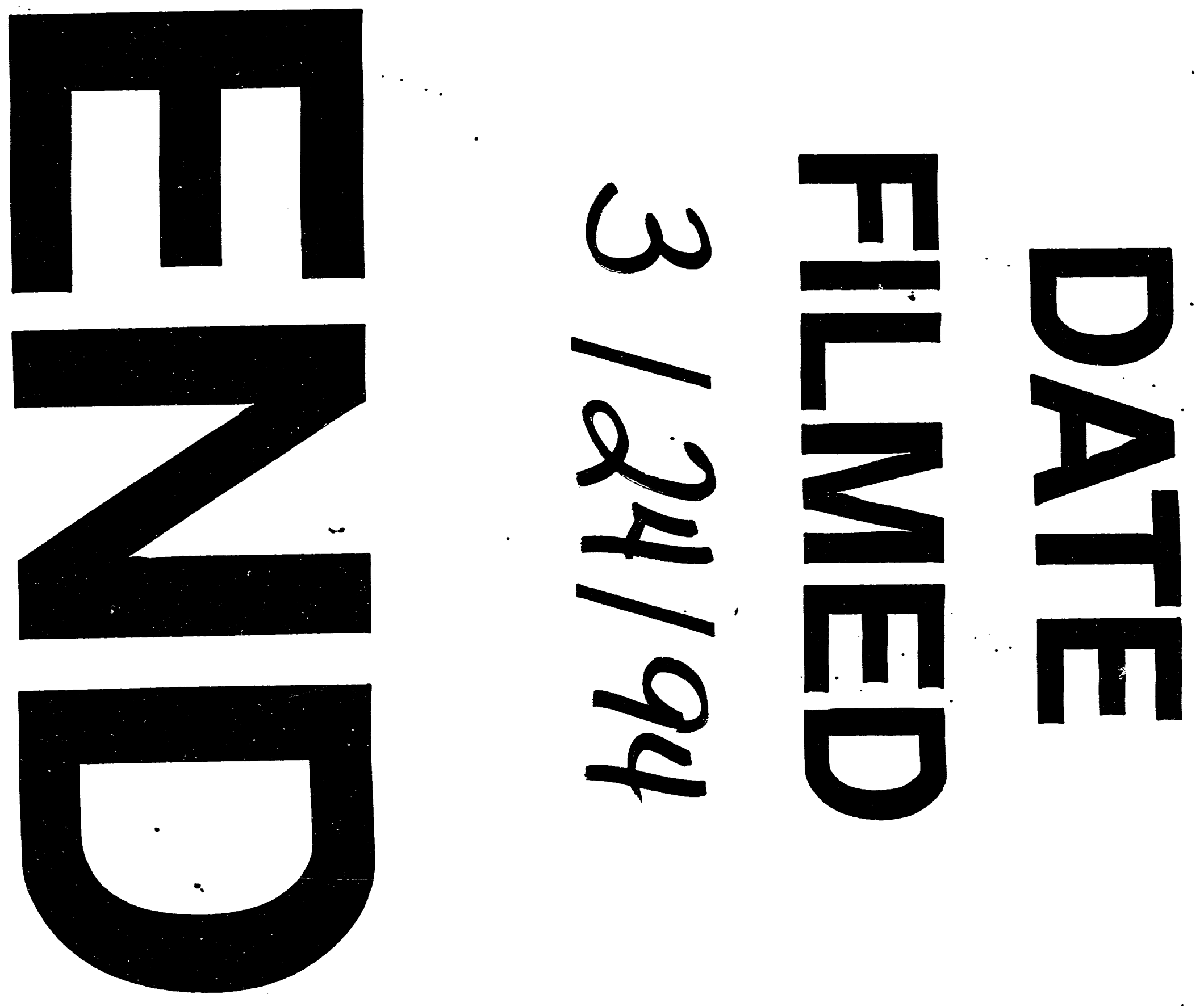
